\title{
Measurements and significance of bio-optical parameters for remote sensing in two subalpine lakes of different trophic state
}

\author{
J.-M. Jaquet ${ }^{1}$, F. Schanz ${ }^{2}$, P. Bossard ${ }^{3}$, K. Hanselmann ${ }^{4}$ and F. Gendre ${ }^{5}$ \\ ${ }^{1}$ Remote Sensing Unit, UNEP-GRID and University of Geneva, 13 rue des Maraîchers, \\ $\mathrm{CH}-1211$ Geneva 4, Switzerland \\ ${ }^{2}$ Institut für Pflanzenbiologie, Limnologische Station, Seestrasse 187, CH-8802 Kilchberg, \\ Switzerland \\ ${ }^{3}$ Lake Research Laboratory EAWAG/ETH, CH-6047 Kastanienbaum, Switzerland \\ ${ }^{4}$ Institut für Pflanzenbiologie der Universität Zürich, Zollikerstrasse 107, CH-8008 Zürich, \\ Switzerland \\ ${ }^{5}$ Institut de Géologie, 11 rue Emile-Argand, $\mathrm{CH}-2000$ Neuchâtel, Switzerland
}

Key words: Water optics, remote sensing, optochemical models, measurement strategies.

\begin{abstract}
Bio-optical measurements were carried out on eutrophic Lake Zug and oligotrophic Lake Lucerne, to provide data and models for the in situ calibration of multispectral imagery collected in 1991, during an AVIRIS flight over Central Switzerland.

The results indicate that Secchi depth, chlorophyll and total suspended solid concentrations, vertical extinction coefficient, absorption coefficient and irradiance reflectance in the PAR region can be used to discriminate between the two lakes. Dissolved organics concentration, scattering and total attenuation coefficients estimates, as well as backscattering probability, are less acceptable, because of instrumental limitations.

Relationships between optical and water quality parameters were investigated and found to behave according to accepted theoretical frameworks. Both lakes exhibited vertical and horizontal heterogeneities in chlorophyll and turbidity, and had contrasting mean bio-optical characteristics: although suspended solid concentrations were similar, transparency was lower in Lake Zug, but reflectance was substantially higher in Lake Lucerne. Water colour determined by chromaticity analysis was blue-green in Lake Lucerne and green in Lake Zug.

Reflectance spectra simulated through a three-component optochemical model did not completely match those derived from in situ measurements, because of lack of site-specific optical cross-sections for suspended minerals and dissolved organics.

The monitoring of water quality in subalpine lakes by remote sensing, both with present and future technology, is discussed and considered as possible, provided that their optical behaviour is known, and preferably expressed by a valid optochemical model.
\end{abstract}




\section{RESUME}

Une série de mesures bio-optiques ont été conduites sur les lacs de Zoug et de Lucerne, dans le but de fournir des données et des modèles pour la calibration de l'imagerie multispectrale, récoltée lors d'un vol AVIRIS de la NASA au-dessus de la Suisse Centrale.

Une étude critique des résultats a été réalisée afin d'estimer la fiabilité des descripteurs biooptiques mesurés ou calculés. Les estimateurs de la transparence Secchi, des concentrations en chlorophylle et matière en suspension totale, des coefficients d'extinction verticale et d'absorption, ainsi que de la réflectance dans le domaine du visible sont considérés comme satisfaisants. En revanche, des imperfections dans l'instrumentation rendent beaucoup moins fiables les estimations de la concentration en carbone organique dissous, des coefficients de diffusion et d'atténuation totale, et de la probabilité de rétrodiffusion.

Les relations mises en évidence entre les paramètres optiques et les descripteurs de la qualité de l'eau se comportent conformément aux cadres théoriques communément admis. Les deux lacs montrent des hétérogénéités verticales et horizontales, visibles dans les profils de chlorophylle et turbidité, et sont clairement contrastés du point de vue bio-optique: bien que les teneurs en suspensoïdes y soient semblables, la transparence est inférieure dans le lac de Zoug, alors que la réflectance est bien supérieure dans le lac de Lucerne. Quant à la couleur de l'eau, déterminée par analyse de chromaticité, elle est bleu-vert et peu saturée pour le lac de Lucerne, et distinctement verte et plus saturée pour le lac de Zoug.

Une tentative d'application d'un modèle optochimique à trois composantes a produit des spectres de réflectance qui ne coïncident pas complètement avec les données obtenues in situ. Cette inadéquation est due à l'absence d'informations sur les coefficients d'absorption et de diffusion spécifiques propres aux lacs étudiés, et à l'imprécision des données sur la matière en suspension et le carbone organique dissous.

On examine finalement la question du suivi par télédétection de la qualité des eaux dans le domaine subalpin. Pour autant que le comportement bio-optique des lacs soit connu, et exprimé de préférence par un modèle optochimique, cette surveillance est considérée comme possible, d'ores et déjà en utilisant les satellites actuels, et plus encore avec la technologie qui sera disponible dans les années à venir.

\section{Introduction and scope}

The colour of water is one of its most obvious organoleptic descriptors. It has a significant, albeit complex, relation to the medium chemical and biological components it contains and is, therefore, considered with transparency and turbidity as a possible indicator of water quality (Gale, 1978).

After the introduction of the Secchi disk (see Tyler, 1968, for a historical perspective) and the early attempts to code colour by means of visual comparison to artificial standards (Forel scale), a theoretically more sound approach evolved through the development of water optics (Jerlov, 1968, Gordon et al., 1975, Kirk, 1983). The advent of earth-resource satellites gave a new impetus towards the elaboration of bio-optical models in oceanography, through linking optical properties to the concentration of dissolved and particulate substances in water (Morel and Prieur, 1977; Prieur and Sathyendranath, 1981; Berthon and Morel, 1992).

In freshwater, the pioneering work of Bukata and co-workers is particularly significant (Bukata et al., $1981 \mathrm{a}, \mathrm{b}$ ). They developed a method relating irradiance reflectance to backscatter and absorption coefficients, themselves functions of water, chlorophyll, suspended minerals and dissolved organic carbon optical crosssections. This modelling approach provided a link between the water optical signa- 
ture (or colour) and water quality, necessary for the use of air- or satelliteborne sensors (Mittenzwey et al., 1988).

To our knowledge, optochemical models have been computed only for a few lakes (Ontario and Ladoga, Bukata et al., 1991 a), and have not yet been referred to extensively in limnological literature. Moreover, apart from the work of Vollenweider (1960) and some data on lakes Zurich (Schanz, 1985, 1986) and Constance (Jewson et al., 1984), little usable information is available on the optical characteristics of subalpine lakes. This is why a campaign of in situ limnological measurements was carried out in Lakes Zug and Lucerne (Central Switzerland) in coincidence with an AVIRIS overpass on July 5th, 1991, within the framework of the AVIRISWISS Project (Itten et al, 1991).

The aim of the work was to (a) critically examine field measurements in both lakes to assess their degree of heterogeneity and comparability, (b) relate optics to water composition, (c) report the baseline bio-optical characteristics, for early Summer conditions, of these two trophically-contrasting lakes and compare their water colour to literature data, (d) test and discuss the application, to a non-uniform water column, of a relationship between reflectance and inherent optical parameters, critical for remote sensing applications, and (e) discuss the applicability of an optochemical model. This will provide a basis for the interpretation of the AVIRIS imagery, to be dealt with in a separate paper, and some clues as to the applicability of remote sensing to alpine inland water-quality monitoring (Jaquet, 1989).

\section{Theoretical background}

After penetrating the lake surface, light undergoes scattering and attenuation due to water itself, as well as dissolved and particulate substances. The underwater light field can be characterized by inherent $(a, b, c$ coefficients; see list of symbols and subsequent text for explanation) and apparent $(K, R)$ optical properties. The latter are dependent on the spatial distribution of radiation (Kirk, 1983), and are readily derived from measurements of underwater irradiance by commonly available equipment.

Relationships between inherent and apparent properties have been established by Gordon et al. (1975) and Kirk (1981) on the basis of Monte Carlo resolutions of the radiative transfer equations. Going one step farther, the dependence of optical characteristics on particulate and dissolved substances was modelled, in the sea, by Morel and co-workers (Morel and Prieur 1977, Morel and Berthon 1989), and, for inland waters, by Bukata and co-workers (Bukata et al. $1981 \mathrm{a}, \mathrm{b}$ ).

Therefore it is feasible to derive the water composition from a set of optical properties determined in situ, through the application of an opto-chemical model (Bukata et al., 1985). Finally, remote determination of the water concentration in total suspended solids (TSS), chlorophyll pigments (Chla) or Dissolved Organic carbon (DOC) is possible in favourable circumstances (Case I waters, in which Chla and TSS covary; Jerlov 1968).

This last procedure totally relies on the vector irradiance reflectance $R(0)$ for PAR (Kirk, 1991), taken just beneath the surface (that is, according to Højerslev (1975), at a depth equal to twice the diameter of the collecting device, in practice 
$10 \mathrm{~cm}) \cdot R(0)$ has been shown to be representative of a layer with a lower limit at a $z_{90}$ depth, equal to the depth at which $E_{\mathrm{d}}$ falls to $37 \%$ of its value at the surface (Gordon and McCluney 1975). This layer is supposed to be uniform with respect to its optical properties, represented by values of absorption $(a)$ and scattering $(b)$ coefficients quasi-invariant with depth. In this case, $a$ and $b$ can be computed by Kirk's (1981) nomogram at mid-euphotic depth $z_{\mathrm{m}}$.

In the event of a non-uniform pigment or TSS profile, it is questionable whether the parameters computed at some specific depth are applicable (Weidemann and Bannister 1986). Gordon (1978) has shown that vertical structure plays an important role in determining $R(0)$. In this case, the assumption of a vertically homogeneous chlorophyll distribution can lead to large errors in the estimation of total pigment in the euphotic zone from satellite data (Sathyendranath and Platt, 1989).

The following equations (1) to (14) are applied to photosynthetically available radiation (PAR) measurements in order to express the water optical properties. The depth index $z$ has been omitted for clarity's sake whenever possible, and the meaning of the abbreviations is found in the Appendix:

\section{Zenith angle in water}

$$
\begin{aligned}
& \theta^{\prime}=\arcsin (\sin (\theta) \cdot 0.75) \\
& \mu(0)=\cos \left(\theta^{\prime}\right)
\end{aligned}
$$

Attenuation coefficients between depth $z_{1}$ and $z_{2}$

$$
K_{\mathrm{d}}=\left|\frac{1}{z_{2}-z_{1}} \cdot \ln \left\{\frac{E_{\mathrm{d}}\left(z_{2}\right)}{E_{\mathrm{d}}\left(z_{1}\right)}\right\}\right|
$$

By analogy, $K_{\mathrm{e}}$ is applicable to net irradiance $E_{\mathrm{n}}$. In practice, $K_{\mathrm{e}} \approx K_{\mathrm{d}}$.

\section{Average cosine}

$$
\mu_{\mathrm{b}}=\frac{E_{\mathrm{n}}}{E_{\mathrm{o}}}
$$

Vector irradiance reflectance at $0 \mathrm{~m}$ depth

$$
R(0)=\frac{E_{\mathrm{u}}(0)}{E_{\mathrm{d}}(0)}
$$

This relation is also applicable to spectral measurements, giving $R(0, \lambda)$. 


\section{Absorption coefficient}

As shown by Jerlov (1974) and Zaneveld (1989), it can be estimated at any depth by

$$
a_{1}=K_{\mathrm{e}} \cdot \mu_{\mathrm{b}}
$$

\section{Scattering coefficient}

Kirk (1984, 1991), using Monte Carlo simulation has derived, implicitly for vertically uniform waters, relationships between the apparent and inherent properties of water $K_{\mathrm{d}}$ and the coefficients of absorption, $a$, and scattering, $b$, at mid-euphotic depth, $z_{\mathrm{m}}$, or averaged over the euphotic depth $\left(z_{\mathrm{eu}}\right)$. Re-arranging his equation, it is possible to estimate $b$ as

$$
b_{2}=\frac{\left(\mu(0) \cdot K_{\mathrm{d}}\left(z_{\mathrm{eu}}\right)\right)^{2}-a^{2}}{a \cdot(0.425 \cdot \mu(0)-0.190)}
$$

for the euphotic zone.

The scattering coefficient is linked to its back-scattering component, $b_{\mathrm{b}}$, through the backscattering probability $B$, so that

$$
b_{\mathrm{b}}=b \cdot B
$$

From Kirk (1983, p. 87), and at $515 \mathrm{~nm}, B$ varies between 0.019 for turbid water (San Diego harbour; $\left.b=1.6 \mathrm{~m}^{-1}\right)$ and 0.044 for clear oceanic water $\left(b=0.04 \mathrm{~m}^{-1}\right)$. Bukata et al. (1979) report, for Lake Ontario, spectrally averaged $B$ varying between 0.010 (pelagic) and 0.033 (coastal). The maximum $B$ value we have found in literature is 0.1462 ("BP phase function" at $530 \mathrm{~nm}$ of Gordon et al. 1975). From all this data, no clear trend does emerge in the relationship between $B$ and turbidity. $B$ can be computed from $K_{\mathrm{d}}, R(0)$ and the total attenuation coefficient, $c$, using the radiative transfer model of Gordon et al. (1975).

\section{Derivation of $b / a$ from $R(0)$ in a stratified waterbody}

According to Kirk (1984, the expression

$$
R(0)=(0.975-0.629 \cdot \mu(0)) \cdot\left(b_{\mathrm{b}} / a\right)
$$

is a fair approximation of the more complex radiative transfer model of Gordon et al. (1975). Setting

$$
\begin{aligned}
& D(\mu(0))=(0.975-0.629 \cdot \mu(0)) \\
& R(0)=D(\mu(0)) \cdot\left(b_{\mathrm{b}} / a\right)
\end{aligned}
$$


$D(\mu(0))$ varies between 0.346 for $\mu(0)=1$ and 0.47 for $\mu(0)=0.8$. It has often been considered as a constant (0.33; Prieur, 1976).

Combining Eq. (7) and (9), one gets

$$
b / a=(1 / D) \cdot R(0)
$$

where

$$
D^{\prime}=D(\mu(0)) \cdot B
$$

The predictability of the ratio of inherent optical parameters $a$ and $b$ depends, therefore, on the knowledge of $D^{\prime}$.

These relationships were initially derived for vertically homogeneous water bodies. In case of stratification of optical parameters (mostly $b$, as in lakes Zug and Lucerne; see Fig. 1), Gordon $(1978,1980)$ has introduced the nation of equivalent homogeneous ocean, whereby $R(0)$ is a function of an average (unweighted or depth-weighted) of $b / a$ over the so-called penetration depth $z_{90}$. An estimate of this penetration depth is also given by (Gordon and McCluney 1975):

$$
z_{90}^{\prime} \approx 1 / K_{\mathrm{d}}
$$

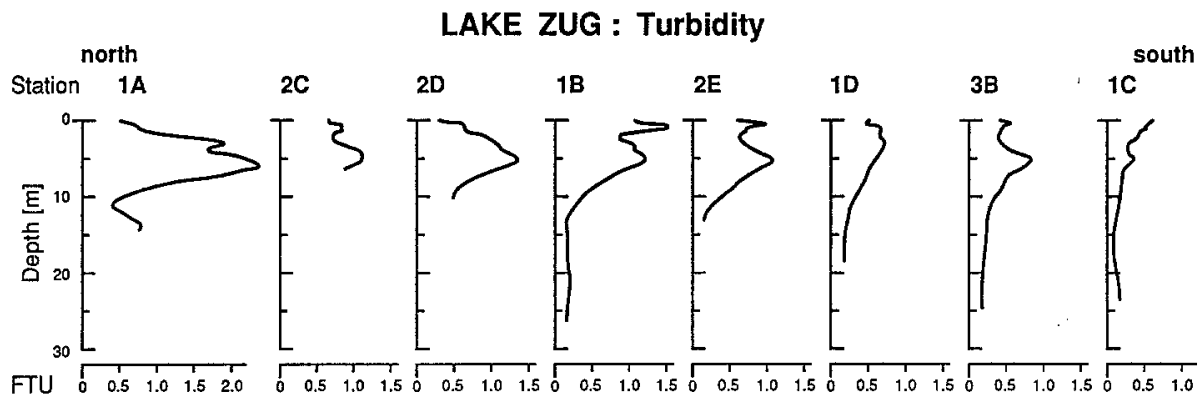

\section{LAKE LUCERNE : Chlorophyll a}

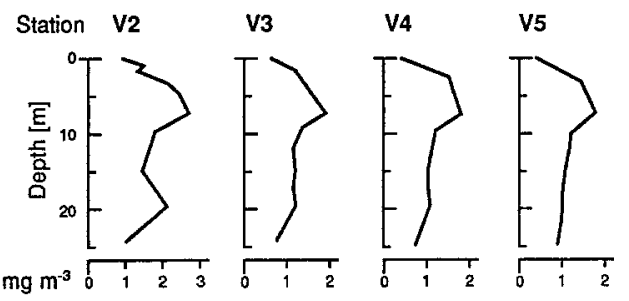

Vitznau Basin
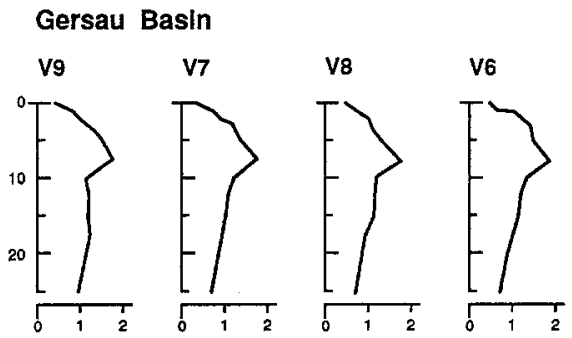

Figure 1. Depth distribution, along geographic profiles, of turbidity (FTU) in Lake Zug and chlorophyll (in situ fluorescence; $\mathrm{mg} \mathrm{m}^{-3}$ ) in Lake Lucerne 
Hence

$$
R_{\mathrm{u}}(0)=D^{\prime} \cdot(b / a)_{\mathrm{u}}
$$

where $(b / a)_{\mathrm{u}}$ is the unweighted mean over $z_{90}$, or

$$
R_{\mathrm{w}}(0)=D^{\prime} \cdot(b / a)_{\mathrm{w}}
$$

where $(b / a)_{\mathrm{w}}$ is the depth-weighted mean computed according to Sathyendranath and Platt (1989):

$$
(b / a)_{\mathrm{w}}=\frac{\int_{0}^{z_{90}}(b / a)(z) \cdot \mathrm{f}(z) \cdot \mathrm{d} z}{\int_{0}^{z_{90}} \mathrm{f}(z) \cdot \mathrm{d} z}
$$

with the weighting function given by

$$
\mathrm{f}(z)=\exp \left[-\int_{0}^{z_{90}} 2 \cdot K_{\mathrm{d}}\left(z^{\prime}\right) \cdot \mathrm{d} z^{\prime}\right]
$$

and approximated by

$$
\mathrm{f}(z)=\exp \left[-\Sigma_{0}^{z_{90}} 2 \cdot K_{\mathrm{d}}\left(z^{\prime}\right) \cdot 1 \mathrm{~m}\right]
$$

For spectral measurements at $0 \mathrm{~m}$ depth, in addition to Eq. (4) already given for spectral irradiance reflectance $R(0, \lambda)$, equations $(15)$ to $(19)$ are appropriate:

\section{TM-equivalent irradiance reflectance (LI-COR)}

$$
R^{\prime}(0, \mathrm{i})=\sum^{s_{\mathrm{s}}} E_{\mathrm{u}}(0, \lambda) / \sum^{s_{\mathrm{i}}} E_{\mathrm{d}}(0, \lambda)
$$

where i corresponds to the index number of Landsat TM satellite visible bands ( 1 to 3 ), and $s_{\mathrm{i}}$ represents the wavelength interval $\left(s_{1}: 450-520 \mathrm{~nm}, s_{2}: 521-600, s_{3}: 630-\right.$ $690)$.

\section{PAR-equivalent irradiance reflectance (LI-COR)}

In order to check the PAR irradiance reflectance given by Eq. (4), other estimates were computed from LI-COR multispectral measurements:

$$
R^{\prime \prime}(0)=\frac{\sum^{\mathrm{PAR}} E_{\mathrm{u}}(0, \lambda)}{\sum^{\mathrm{PAR}} E_{\mathrm{d}}(0, \lambda)}
$$

where PAR represents the interval between 400 and $700 \mathrm{~nm}$, and

$$
R^{\prime \prime \prime}(0)=\frac{\sum^{\mathrm{s}} E_{\mathrm{u}}(0, \lambda)}{\sum^{\mathrm{s}} E_{\mathrm{d}}(0, \lambda)}
$$


Table 1a. Bio-optical parameters representative of DSPRS layer (depth of solar radiation penetration for remote sensing: $z_{90}$ ). TSS=Total Suspended Solids. For all other symbols, see Appendix

\begin{tabular}{|c|c|c|c|c|c|c|c|c|c|c|c|c|}
\hline \multirow[b]{2}{*}{ Zug } & \multirow[b]{2}{*}{$z_{\mathrm{sd}}$} & \multirow[b]{2}{*}{$z_{90}$} & \multirow[b]{2}{*}{$z_{90}^{\prime}$} & \multirow[b]{2}{*}{$z_{\mathrm{eu}}$} & \multirow[b]{2}{*}{$\mu(0)$} & \multirow[b]{2}{*}{$R(0)$} & \multirow[b]{2}{*}{$K_{\mathrm{d}}$} & \multicolumn{5}{|c|}{ unweighted } \\
\hline & & & & & & & & $a_{1 \mathrm{u}}$ & $a_{3 \mathrm{u}}$ & $b_{2}^{1}$ & $b_{3 \mathrm{u}}$ & $c_{1 \mathrm{u}}$ \\
\hline Lucerne & & & & & & & & & & $b_{4 u}$ & $c_{2 u}$ & \\
\hline Units & $\mathrm{m}$ & $\mathrm{m}$ & $\mathrm{m}$ & $\mathrm{m}$ & & & $\mathrm{m}^{-1}$ & $\mathrm{~m}^{-1}$ & $\mathrm{~m}^{-1}$ & $\mathrm{~m}^{-1}$ & $\mathrm{~m}^{-1}$ & $\mathrm{~m}^{-1}$ \\
\hline \multicolumn{13}{|l|}{ Station } \\
\hline $\begin{array}{l}\mathbf{1 A} \\
\mathbf{3 E}\end{array}$ & $\begin{array}{l}3.6 \\
3.9\end{array}$ & $\begin{array}{l}1.7 \\
2.1\end{array}$ & $\begin{array}{l}1.6 \\
1.7\end{array}$ & $\begin{array}{r}8.0 \\
>10\end{array}$ & $\begin{array}{l}0.80 \\
0.89\end{array}$ & $\begin{array}{l}0.023 \\
0.020\end{array}$ & $\begin{array}{l}0.63 \\
0.59\end{array}$ & $\begin{array}{l}0.50 \\
0.44\end{array}$ & $\begin{array}{l}0.60 \\
0.66\end{array}$ & $\begin{array}{l}0.71 \\
0.47\end{array}$ & $\begin{array}{l}0.83 \\
0.77\end{array}$ & $\begin{array}{l}0.57 \\
0.32\end{array}$ \\
\hline $2 D$ & 4.9 & 2.4 & 2.0 & $>10$ & 0.92 & 0.018 & 0.50 & 0.42 & 0.74 & 0.79 & 0.60 & 0.27 \\
\hline $2 \mathrm{E}$ & 5.1 & 1.9 & 2.1 & $>10$ & 0.94 & 0.013 & 0.48 & 0.38 & 0.60 & 0.74 & 0.77 & 0.33 \\
\hline 3B & 6.2 & 2.8 & 2.8 & $>10$ & 0.95 & 0.015 & 0.36 & 0.28 & 0.56 & 0.50 & 0.40 & - \\
\hline Mean & 4.7 & 2.2 & & & 0.90 & 0.018 & 0.51 & 0.40 & 0.63 & 0.64 & 0.67 & 0.37 \\
\hline $\mathrm{CI}^{3}$ & 1.3 & 0.5 & & & 0.08 & 0.005 & 0.13 & 0.10 & 0.08 & 0.18 & 0.22 & 0.19 \\
\hline V4 & 6.1 & 3.7 & 3.8 & 16.0 & 0.86 & 0.059 & 0.26 & 0.18 & - & - & 0.78 & 0.97 \\
\hline V7 & 6.4 & 4.2 & 4.5 & 18.0 & 0.93 & 0.046 & 0.22 & 0.17 & - & - & 0.95 & 1.12 \\
\hline V12 & 5.6 & 3.9 & 3.8 & 17.5 & 0.92 & 0.066 & 0.26 & 0.18 & - & - & 1.14 & 1.31 \\
\hline V15 & 6.8 & 4.2 & 4.3 & 12.5 & 0.81 & 0.063 & 0.23 & 0.19 & - & - & - & - \\
\hline Mean & 6.2 & 4.0 & & & 0.88 & 0.059 & 0.24 & 0.18 & - & - & 0.98 & 1.13 \\
\hline CI & 0.7 & 0.3 & & & 0.08 & 0.010 & $\mathbf{0 . 0 3}$ & 0.01 & - & - & 0.29 & 0.27 \\
\hline Formula & Zug & & (11) & & (1b) & (4) & (2) & $(5)$ & (21) & (6b) & $(22)$ & $(20)$ \\
\hline Formula & Lucerne & & & & & (24) & & & & & (26) & $(25)$ \\
\hline Eval. ${ }^{4}$ & G & $\mathbf{G}$ & G & G & G & $\mathbf{S}$ & G & G & $\mathbf{A}$ & $\mathbf{A}$ & $\mathbf{A}$ & $\mathbf{P}$ \\
\hline
\end{tabular}

${ }^{1}$ Computed by (6) from average of $K_{\mathrm{d}}$ and $a_{1}$ over photic depth $z_{\text {eu }}$

${ }^{2}$ Integrated sample over $z_{\mathrm{sd}}$

${ }^{3}$ Confidence interval $(0.05$ level)

${ }^{4}$ Evaluation: G (good), S (satisfactory), A (acceptable), P (poor)

${ }^{5}$ Mean $=77.1$ if anomalous St. $2 \mathrm{E}$ is excluded

where s represents the interval of TM visible bands (450-600 and $630-690 \mathrm{~nm}$ ), approximately equivalent to PAR.

\section{Above-water irradiance reflectance (EXOTECH)}

$$
R_{\mathrm{e}}(\mathrm{i})=Q \cdot \frac{L_{\mathrm{u}}(\mathrm{i})}{E_{\mathrm{d}}(\mathrm{i})}
$$

where $\mathrm{i}$ corresponds to the index number of TM-equivalent channels of the EXOTECH instrument. $Q$ is theoretically equal to $\pi$ (Lambertian reflector), but has 
Table 1a (continued)

\begin{tabular}{|c|c|c|c|c|c|c|c|c|c|c|c|}
\hline \multicolumn{6}{|c|}{ unweighted } & \multicolumn{4}{|c|}{ weighted } & \multicolumn{2}{|c|}{ Integrated $^{2}$} \\
\hline \multirow[t]{2}{*}{$c_{3 u}$} & $b_{3} / a_{1 \mathrm{u}}$ & $D_{c}^{\prime}$ & $1 / D_{c}^{\prime}$ & $D(\mu(0))$ & $B$ & $a_{1 \mathrm{w}}$ & $b_{3 w}$ & $c_{3 \mathrm{w}}$ & $b_{3} / a_{1 \mathrm{w}}$ & Chl $a$ & TSS \\
\hline & $b_{4} / a_{1 \mathbf{u}}$ & & & & & & $b_{4 \mathrm{w}}$ & & $b_{4} / a_{1 \mathrm{w}}$ & & \\
\hline$m^{-1}$ & & & & & & $\mathrm{~m}^{-1}$ & $\mathrm{~m}^{-1}$ & $\mathrm{~m}^{-1}$ & & $\mu \mathrm{gl}^{-1}$ & $\mathrm{mgl}^{-1}$ \\
\hline 1.33 & 1.67 & 0.014 & 73.4 & 0.47 & 0.029 & 0.50 & 0.84 & 1.34 & 1.67 & 4.18 & 2.50 \\
\hline 1.21 & 1.08 & 0.012 & 82.4 & 0.42 & 0.029 & 0.46 & 0.77 & 1.23 & 1.68 & 4.04 & 1.90 \\
\hline 1.02 & 1.43 & 0.018 & 56.7 & 0.40 & 0.044 & 0.43 & 0.44 & 0.87 & 1.03 & 3.46 & 1.17 \\
\hline 1.15 & 2.02 & 0.006 & 159.2 & 0.38 & 0.016 & 0.42 & 0.89 & 1.31 & 2.12 & 4.58 & 1.80 \\
\hline 0.68 & 1.44 & 0.010 & 95.9 & 0.38 & 0.028 & 0.28 & 0.40 & 0.68 & 1.44 & 2.18 & 1.37 \\
\hline 1.08 & 1.53 & 0.012 & $93.5^{5}$ & 0.41 & 0.029 & 0.42 & 0.67 & 1.09 & 1.59 & 3.69 & 1.75 \\
\hline 0.31 & 0.43 & 0.005 & 48.9 & 0.05 & 0.012 & 0.10 & 0.29 & 0.37 & 0.49 & 1.16 & 0.64 \\
\hline 0.97 & 4.25 & 0.017 & 57.9 & 0.43 & 0.040 & 0.20 & 0.67 & 0.86 & 3.42 & 1.48 & 1.11 \\
\hline 1.12 & 6.08 & 0.010 & 100.5 & 0.39 & 0.026 & 0.18 & 0.81 & 0.98 & 4.62 & 0.98 & 1.37 \\
\hline 1.31 & 6.33 & 0.014 & 73.8 & 0.40 & 0.034 & 0.19 & 0.93 & 1.12 & 4.87 & 1.05 & 1.35 \\
\hline- & - & - & - & - & - & - & - & - & - & 1.38 & 1.19 \\
\hline 1.15 & 5.55 & 0.014 & 77.4 & 0.41 & 0.033 & 0.19 & 0.80 & 0.99 & 4.30 & 1.22 & 1.26 \\
\hline 0.29 & 1.82 & 0.006 & 34.6 & 0.04 & 0.012 & 0.01 & 0.21 & 0.17 & 1.02 & 0.30 & 0.15 \\
\hline$a_{1}+b_{3}$ & & $R(0)$ & $(10 a)$ & $(8 b)$ & $(10 b)$ & & (22) & $a_{1}+b_{3}$ & & & \\
\hline$a_{1}+b_{4}$ & & $\overline{\left(b / a_{1}\right)}$ & & & & & (26) & $a_{1}+b_{4}$ & & & \\
\hline $\mathbf{A}$ & $\mathbf{A}$ & A & $\mathbf{A}$ & $\mathbf{G}$ & $\mathbf{P}$ & $\mathbf{S}$ & $\mathbf{A}$ & $\mathbf{A}$ & $\mathbf{A}$ & $\mathbf{G}$ & $\mathbf{G}$ \\
\hline
\end{tabular}

been found, by Monte Carlo simulation, to vary according to zenith angle (Jerome et al. 1989). Following the recommendations of Kirk (1984, p. 117), we have set $Q=5$. By analogy with Eq. (17),

$$
R_{\mathrm{ex}}(0)=Q \cdot \frac{\sum_{1}^{3} L_{\mathrm{u}}(\mathrm{i})}{\sum_{1}^{3} E_{\mathrm{d}}(\mathrm{i})}
$$

with the interval of summation representing the three visible bands of the instrument. 


\section{Quantitative expression of water colour by chromaticity}

Water colour can be expressed quantitatively in terms of dominant wavelength (hue) and saturation in the so-called CIE 1931 chromaticity system (see for instance Smith et al., 1973 and Davies-Colley et al., 1988). Narrow-band $x, y, z$ chromaticity coordinates were computed for surface water samples from $E_{\mathrm{u}}(0, \lambda)$ and $E_{\mathrm{d}}(0, \lambda)$ following the procedure outlined in Table 1(3.3.8) of Wyszecki and Stiles (1982).

Additionally, in order to extract colour information from broad-band TM or TM-equivalent measurements, the colour matching functions $\left\{x_{\mathrm{b}}, y_{\mathrm{b}}, z_{\mathrm{b}}\right\}_{\lambda}$ (Wyszecki and Stiles 1982, p. $725 \mathrm{sq}$ ) were summed over TM intervals and multiplied by the value of $E_{\mathrm{u}}(\mathrm{i})$ or $E_{\mathrm{d}}(\mathrm{i})(\mathrm{EXOTECH})$ or the average of $E_{\mathrm{u}}(0, \lambda)$ and $E_{\mathrm{d}}(0, \lambda)$ (LI-COR), before proceeding with the methodology outlined above.

\section{Measurements and lakes considered}

In order to collect ground data representative of airborne spectographic measurements, field work had to be conducted in the shortest possible time, and simultaneously on both lakes. This involved several teams using, regretably, not totally standardized procedures, and different instruments. A fair amount of efforts then had to be devoted to conversion of measurements, to ensure they were comparable.

\subsection{Lake Zug}

Chlorophyll $a$ concentrations were measured in water samples (integrated or discrete) collected at stations 1A, 3E, 2D, 2E and 3B (Fig. 2), and are given in Tables $1 \mathrm{a}-\mathrm{b}$ as an average over Secchi depth. Total suspended solid concentrations are available over Secchi depth at stations 1A, 1B, 1C, 1D, 2C, 2D, 2E, 3B and 3E.

Downwelling and upwelling vector irradiance in the PAR spectral region $(400-700 \mathrm{~nm})$ was measured above water and at various depths, at stations indicated in Table 2, by a cosine underwater quantum sensor LI-190SB from LI-COR (Lincoln, Nebraska, USA), and scalar irradiance by a spherical (4 $\pi$ collector) quantum sensor LI-193SB. Both sensors were connected to a LI-185B quantum meter $(\mu \mathrm{E}$ $\mathrm{m}^{-2} \mathrm{~s}^{-1}$ ). PAR attenuation coefficient, average cosine, irradiance reflectance and absorption coefficient were computed using relations Eq. (2), Eq. (3), (4) and (5), respectively.

Spectral up- and downwelling vector irradiance was measured above water between $300-1110 \mathrm{~nm}$ and in water between $300-850 \mathrm{~nm}$ at $0,1,2.5,5,7.5$ and $10 \mathrm{~m}$ depth by means of a LI-1800UW (Serial no. UWS163) spectroradiometer (Wm-2

Figure 2. Location maps of Lakes Zug and Lucerne, with positions of stations 


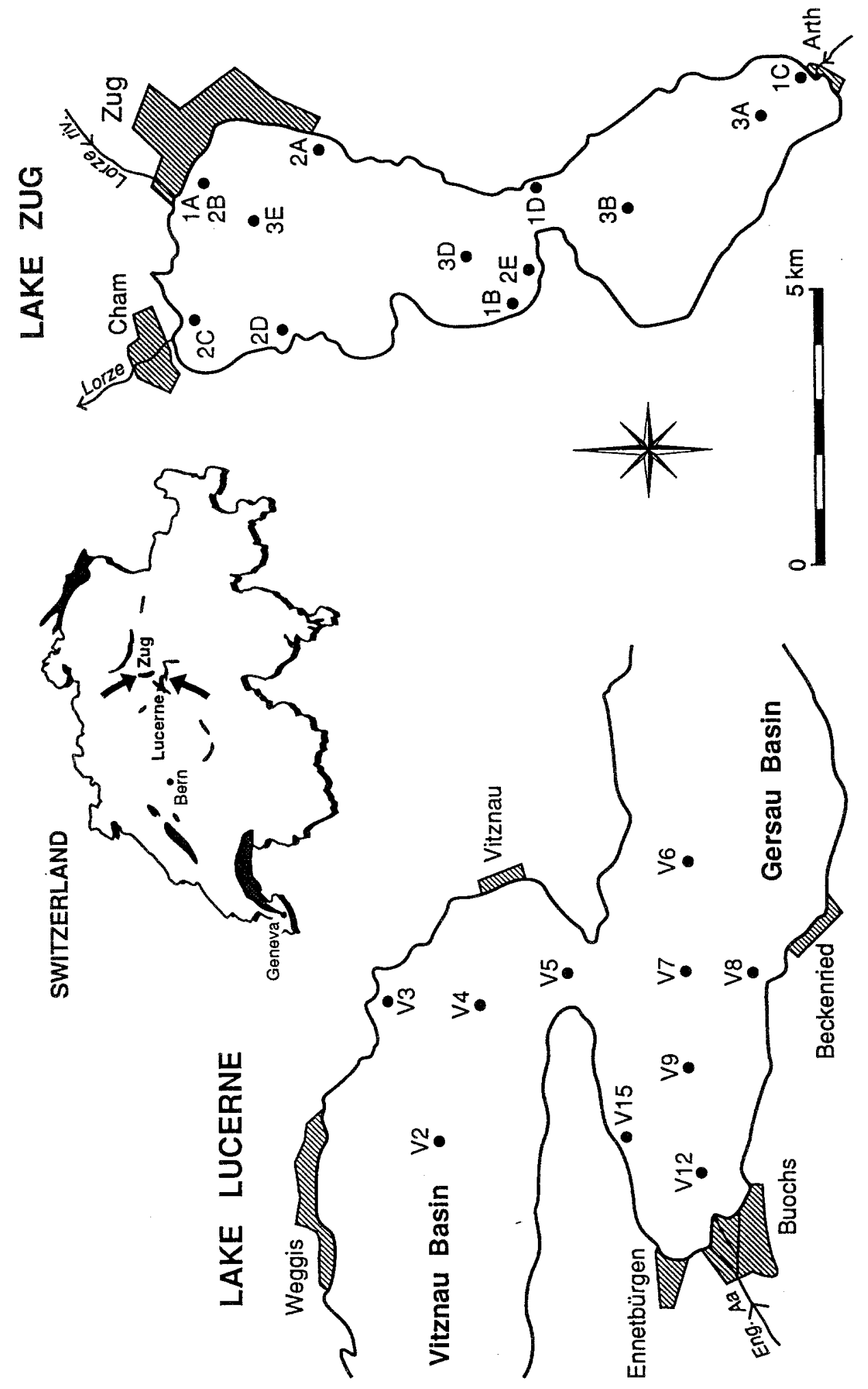




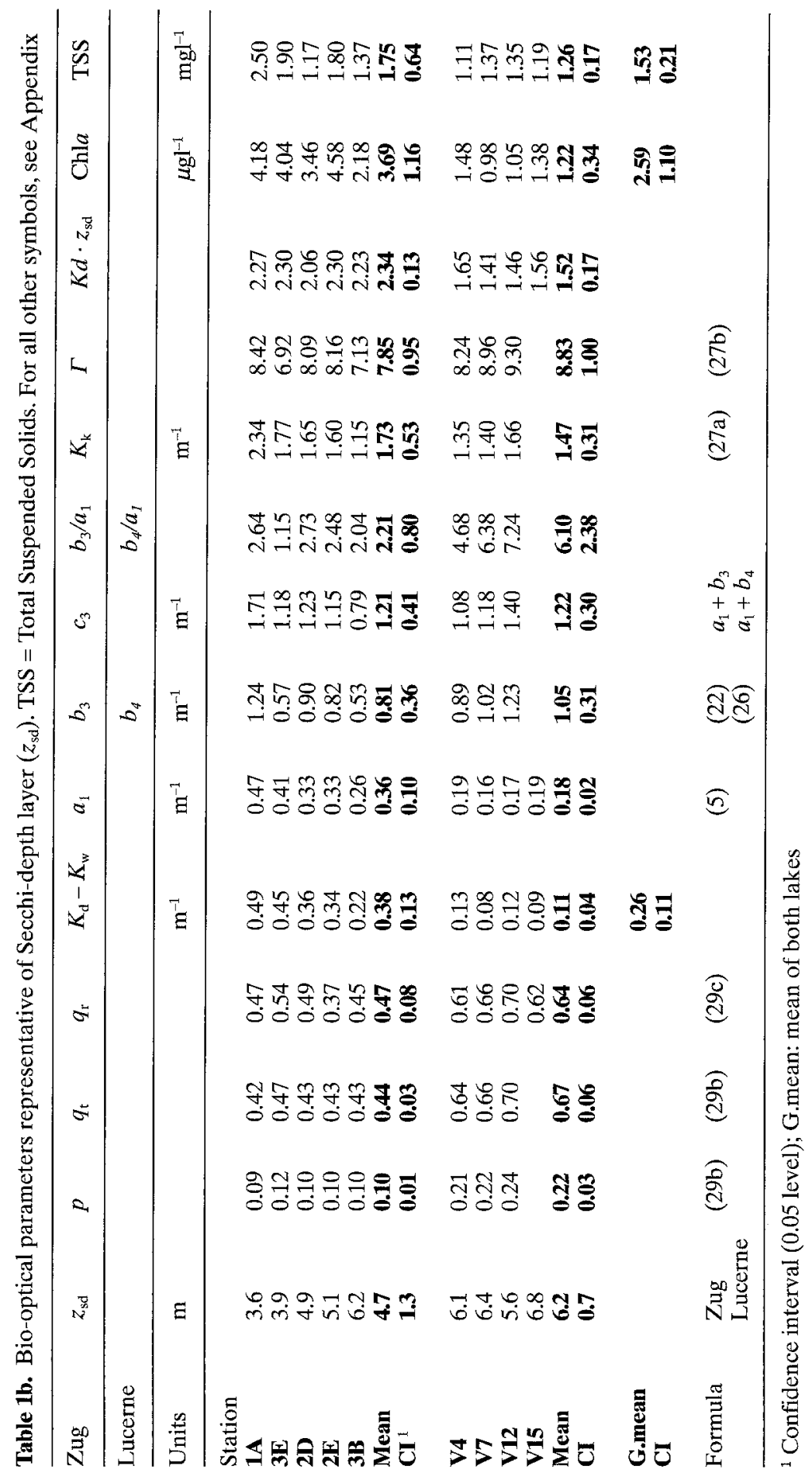


$\mathrm{nm}^{-1}$, at $2 \mathrm{~nm}$ intervals). To allow for a certain time-lag between up and down measurements, a small correction (multiplication factor of $0.946-1.034$ ) was applied to computed $R(0, \lambda)$. Spectral irradiance reflectance, TM-equivalent and PARequivalent irradiance reflectance were computed using Eq. (4), (15) and (16), respectively (Fig. 3).

Beam attenuation was measured using a light sensor (PAR sensor, LI-190SB), fixed at a distance of $1 \mathrm{~m}$ from a laser source $\left(\lambda_{\max }=634,1 / 2\right.$ bandwidth between 626 and $642 \mathrm{~nm}$ ). The beam was protected from downward irradiance by a U-shaped metal pipe. The total or beam attenuation coefficient was estimated by

$$
c_{1}=\left(\ln \left(\operatorname{Tr}_{634}\right)\right) \cdot 1.0 \mathrm{~m}^{-1}
$$

where $T r_{634}$ is the transmissivity computed with reference to air. Although $c$ displays some spectral variation (due to $a$; Bukata et al. 1979, Fig. 3), $c_{1}$ and, to a lesser extent, $c_{2}$ estimates can be considered as a fair approximation of $c$ for the PAR interval.

Absorption measured at $357 \mathrm{~nm}$ in $10 \mathrm{~cm}$ cuvettes on filtered samples yielded

$$
a_{3}=-\left(\ln \left(\operatorname{Tr}_{357}\right)\right) \cdot 0.1 \mathrm{~m}^{-1}
$$

This measurement can be used to estimate DOC concentration, such as done by Vertucci and Likens (1991).

In addition to the computation of scattering coefficient by means of Eq. (6), another estimate was tentatively derived from turbidity expressed as FTU (formazin turbidity units) and measured using a prototype forward-scattering meter (Vangriesheim et al., 1992):

$$
b_{3}(z) \approx S \cdot \text { Turbidity expressed in FTU }
$$

where $S$ is a conversion factor approximately equal to $1 \mathrm{FTU} \mathrm{m}^{-1}$. This empirical relationships has been proposed by Di Toro (1978) and Weidemann and Bannister (1986).

On both lakes, a hand-held EXOTECH 100BX spectrometer was used for sun, zenith and water spectral measurements. This instrument has 4 channels equivalent to those of Landsat TM (bluegreen, green, red and near-infrared). Six to ten readings were collected at each station. For sky irradiance measurements, the instrument was fitted with a cosine lens and only the highest reading was retained. For water leaving radiance, the instrument, fitted with $15^{\circ}$ lenses, was aimed at the water surface, $50 \mathrm{~cm}$ above it and at such angle to minimize sun glint and sky reflection. In this case the significant value is either the lowest one, or the arithmetic average.

\subsection{Lake Lucerne}

Water samples were collected from 16 stations in the epilimnions of Vitznauer and Gersauer basins (Fig. 2), out of which four were retained for comparative optical 


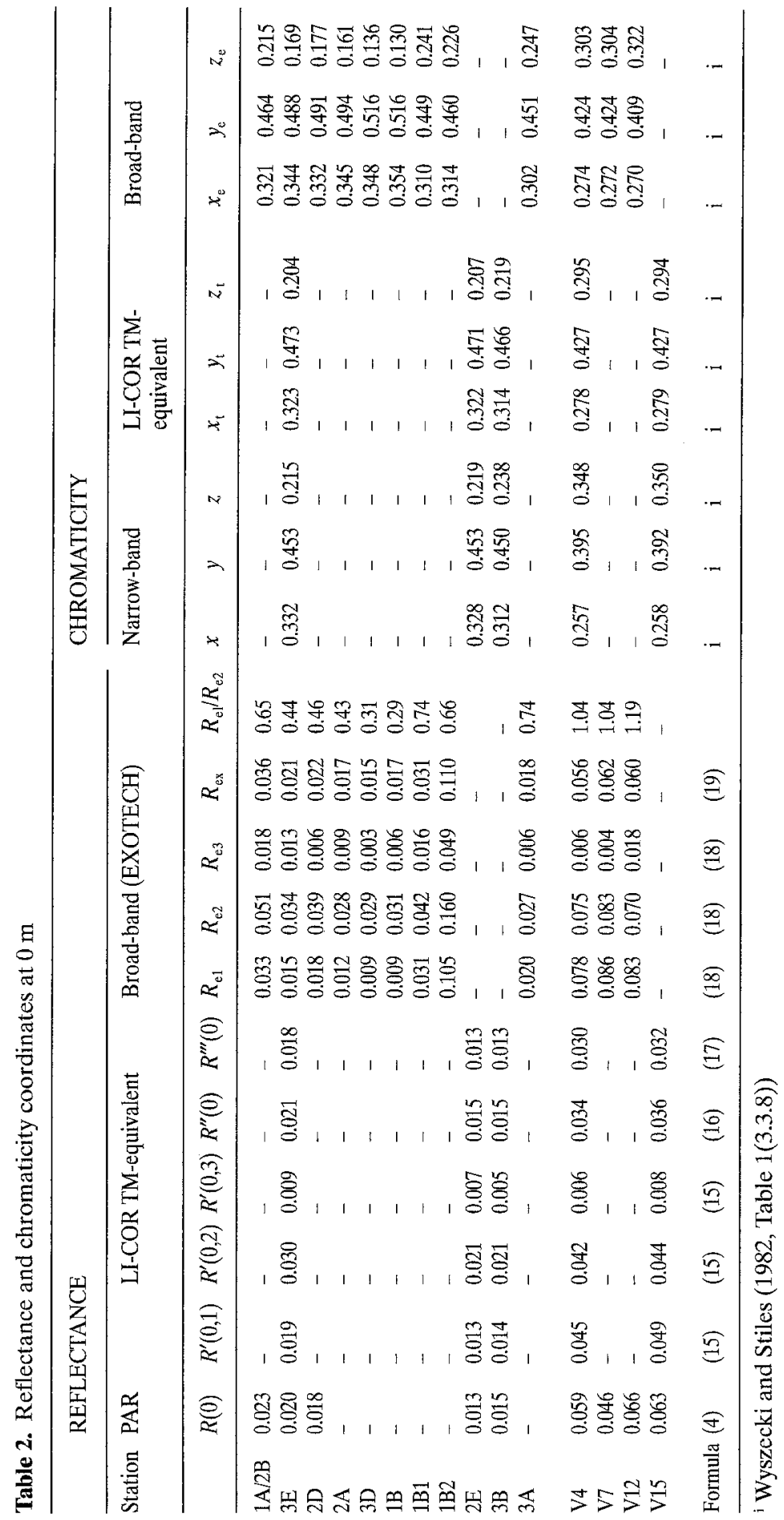




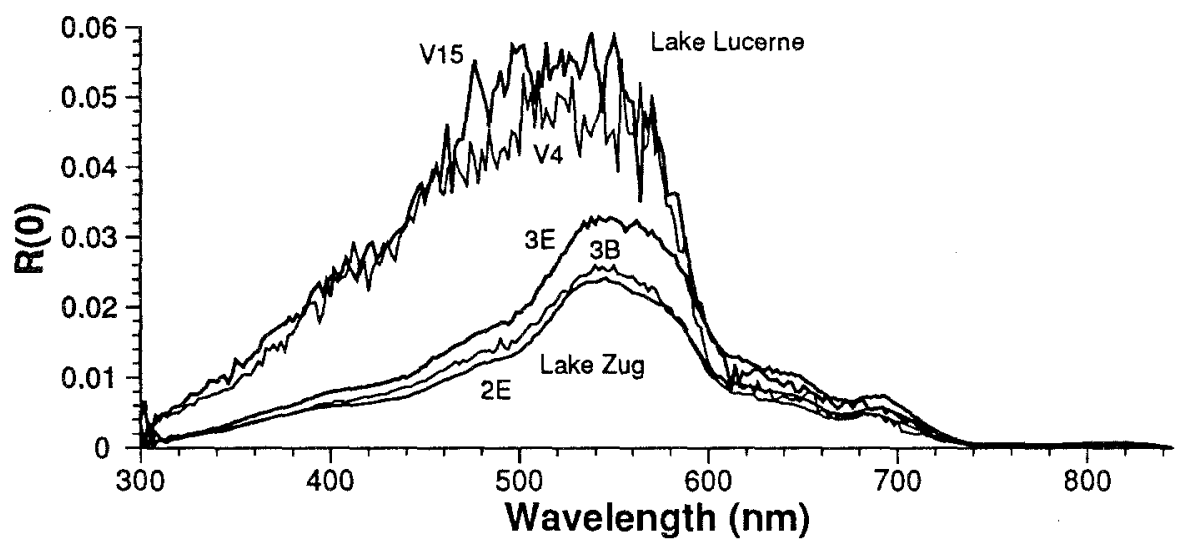

Figure 3a. Narrow-band, spectral vector irradiance reflectance at $0 \mathrm{~m}(R(0))$, corrected for timelag between upward and downward measurements. Stations Zug: 2E, 3B, 3E. Lucerne: V4, V15

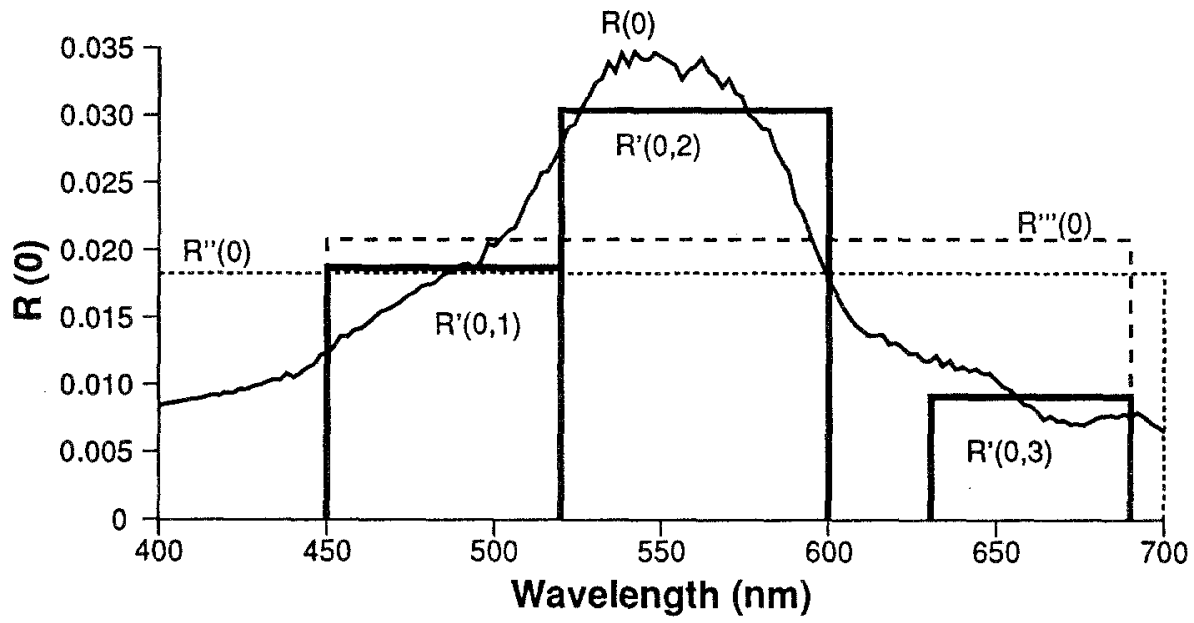

Figure 3b. Various estimates of spectral vector irradiance reflectance at $0 \mathrm{~m}$; station 3E: narrowband $(R(0))$, mean of narrow-band measurements over PAR $\left(R^{\prime \prime}(0)\right)$, TM-equivalent $\left(R^{\prime}(0, \mathrm{i})\right)$, mean of TM-equivalent $\left(R^{\prime \prime \prime}(0)\right)$

measurements (V4, V7, V12, V15). Water was collected with a Friedinger sampler or with a polyethylene hose for integrated samples.

The photosynthetically active radiation (PAR) was measured above and below the water surface with spherical quantum sensors (LI-193SB, LI-COR Inc.). One sensor was fixed on the boat to monitor relative changes of incident PAR above the surface. For the measurement of upwelling and downwelling ambient PAR underwater, two sensors were attached to a frame, one pointing upwards, one downwards. The sensors were separated by a horizontal circular black plate (diameter $45 \mathrm{~cm}$ ) to enable measurements of scalar irradiance $E o_{\mathrm{d}}$ and $E o_{\mathrm{u}}$. The sensors were connect- 
ed to a LI-COR 1000 datalogger, which integrated at each depth the $10 \mathrm{sec}$ readings expressed in $\mu \mathrm{Em}^{-2} \mathrm{~s}^{-1}$. Incident PAR was also continuously monitored on the roof of the Lake Research laboratory, some $8-10 \mathrm{~km}$ from the sampling sites, using a cosine-corrected quantum sensor (LI-192SB).

Scalar reflectance was estimated from scalar irradiance (Fig. 3) using the following relationship derived from Monte-Carlo calculations:

$$
R \mathrm{o}(0)=(1.085-0.384 \cdot \mu(0)) \cdot\left(b_{\mathrm{b}} / a\right)
$$

(Bannister 1990), with $R o(0)=E o_{\mathrm{u}} / E o_{\mathrm{d}}$. Combining Eq. (8) and (23), we get the expression for vector reflectance

$$
R(0)=R o(0) \cdot F
$$

with $F=(0.975-0.384 \cdot \mu(0)) /(1.085-0.384 \cdot \mu(0))$. This factor varies between 0.494 for $\mu(0)=1$ and 0.699 for $\mu(0)=0.6$, and depends on the sun zenith angle.

Water temperature, conductivity and transmissivity (at $680 \mathrm{~nm}$ ) were measured with a Meereselektronik CTD profiler at the sampling stations V4 and V7. A defect disabled measurements at stations V12 and V15. The total attenuation coefficient was calculated by

$$
c_{2}(z)=-\left(\ln \left(\operatorname{Tr}_{680}(z)\right)\right) \cdot 0.075 \mathrm{~m}^{-1}
$$

and the scattering coefficient by

$$
b_{4}(z)=c_{2}(z)-a_{1}(z)
$$

Chlorophyll was measured spectrophotometrically after ethanol extraction, according to the Deutsche Einheitsverfahren (DEV L16, 1985), in one complete $25 \mathrm{~m}$ profile at station V2, as well as in surface, $0 \mathrm{~m}$ to Secchi depth and $0-25 \mathrm{~m}$ integrated samples at the other stations. Profiles of chlorophyll concentration were calculated from in situ fluorometer measurements at all stations, after calibration with the data obtained from the DEV method at station V2. In situ fluorometry was conducted with a Variosens II pulse-light fluorometer (Impulsphysik $\mathrm{GmbH}$, Hamburg) according to Uehlinger (1985). Dry weight was obtained by filtration on GFF glass fiber filters from $0 \mathrm{~m}$ and integrated samples.

\subsection{Limnological setting}

Lake Zug is an elongated waterbody, with a mean depth of $83 \mathrm{~m}$ and a high aspect ratio of 0.032 (Imboden et al. 1988). Its southern basin has a maximum depth of $197 \mathrm{~m}$ and is isolated by a peninsula from the shallower northern basin, where both inlet and outlet are located (Lorze rivers, Fig. 2). The mean water residence time is 14.2 years, and most allochtonous inputs of nutrients go into the northern part of the lake, where the towns of $\mathrm{Zug}$ and Cham are located. Lake Zug is still clearly eutrophic (Fahrni and Liechti, 1984). 
Lake Lucerne (mean depth $104 \mathrm{~m}$, maximum depth $214 \mathrm{~m}$ ) is a fjord-like system of connected basins which differ in their mixing patterns. The two prealpine basins of concern in this study, Gersauer and Vitznauer Basins, are surrounded by mountains. They mix incompletely and to different depths each year. Maximum depth are $214 \mathrm{~m}$ for Gersauersee (east of station V6) and $151 \mathrm{~m}$ for Vitznauersee (close to stn. $\mathrm{V} 2$ ). The basins are separated by an underwater ridge some $40 \mathrm{~m}$ below the lake surface. The river Engelberger Aa enters Gersauersee in a relatively shallow part at Buochs, and is responsible for occasional turbidity caused by flooding (Fig. 2).

These formerly oligotrophic basins slowly became mesotrophic between 1950 and 1980 . Since then, the lake has been undergoing a rapid process of "re-oligotrophication". Total phosphorus concentrations during winter overturn reached maximum values of $27 \mathrm{mg} \mathrm{m}^{-3}$ in 1980 . Since then, total $\mathrm{P}$ has decreased to less than $10 \mathrm{mg} \mathrm{m}^{-3}$ at present. Maximum Cassimilation $\left(300 \mathrm{~g} \mathrm{C} \mathrm{m}^{-2} \mathrm{yr}^{-1}\right)$ was reached in the early eighties, and subsequently dropped to $150 \mathrm{~g}$ by 1991 (Ambühl and Bossard, unpublished data).

\section{Results}

\subsection{Water quality parameters}

In lakes Zug and Lucerne, there were marked variations in turbidity and chlorophyll $a$ with depth (Fig. 1).

In Lake Zug, for instance, a definite turbidity maximum occurs at an approximate depth of $5 \mathrm{~m}$, together with a smaller surface peak gaining in importance from North to South (Stn. 3B). The amplitude of the maximum also decreases from North to South. These patterns are confirmed by the results of chlorophyll measurements (Table 1), and can be ascribed to the stronger anthropic impact on the Northern part of the watershed (industries, cities and agriculture; Fig. 2).

In Lake Lucerne, a vertical trend also exists, shown by chlorophyll profiles, but with a maximum deeper $(7.5 \mathrm{~m})$ than in Lake Zug (Fig. 1). There is no marked contrast in chlorophyll concentration between Vitznau and Gersau basins $(1.3-1.5 \mathrm{mg}$ $\mathrm{m}^{-3}$ ), which differ, however, in suspended solid concentration, slightly higher in Gersau because of the influence of the Engelberger Aa river (Bossard et al. 1991): Vitznau (V7): $1.11 \mathrm{mg} \mathrm{1}^{-1}$; Gersau (V7): $1.37 \mathrm{mg} \mathrm{l}^{-1}$ (Table 1b).

In general terms, as seen in Table 1a, Lake Zug chlorophyll levels (mean of $\left.3.69 \mu \mathrm{g}^{-1}\right)$ are $2-3$ times higher than those of Lake Lucerne $\left(1.26 \mu \mathrm{g}^{-1}\right)$, with a smaller contrast in supended solids (1-2 times: 1.75 vs. $\left.1.26 \mathrm{mg} \mathrm{l}^{-1}\right)$. As a consequence, it can be expected that the overall optical properties of both water bodies will be somewhat different. In addition, the vertical stratification will have to be considered in the computation of these properties.

\subsection{Relationships between optical and water-quality parameters}

The optical properties $a_{1}, a_{3}, b_{3}, b_{4}$ and $c$, determined at discrete levels, have been aggregated over the following layers: 
- Depth of sunlight penetration for remote sensing (DSPRS; Gordon and McCluney, 1975): this layer extends from the surface down to $z_{90}$, and its optical properties critically influence the magnitude of $R(0)$, key-factor for remote sensing applications. Table 1a presents unweighted and depth-weighted estimates following Eq. $(13-14)$.

- Secchi depth $\left(z_{\text {sdd }}\right)$ : this layer, with $z_{\text {sd }}$ about the double of $z_{90}$ (Table 1a), represents a commonly used aggregate sampling unit for water quality parameters. The values of optical properties representative of this layer will be compared to Secchi readings for validation purpose (Table $1 \mathrm{~b}$ ).

- Euphotic layer $\left(z_{\mathrm{eu}}\right)$ : representative values of $K_{\mathrm{d}}$ and $a_{1}$ for this layer have been used to compute a scattering coefficient estimate $b_{2}$ by means of relation (6), strictly valid only in case of an optically non stratified waterbody (Table 1a).

Secchi depth has been routinely measured for many years to gain an insight into the light climate of the uppermost water layers. It is also considered as an empirical, general-purpose water quality indicator. We examine here some of its relationships with bio-optical parameters measured during the study, in order to test its possible applicability in providing ground-truth data suitable for remote sensing studies.

Preisendorfer (1986) states that Secchi readings yield a quantitative estimate of the photopic attenuation coefficient (an apparent optical property)

$$
K_{\mathrm{k}}=K_{\mathrm{d}}+c
$$

related to Secchi depth in the following way:

$$
K_{\mathrm{k}}=\Gamma / z_{\mathrm{sd}}
$$

where $\Gamma$, a contrast transmittance factor, is a function of the disk inherent and liminal contrasts, themselves affected by various factors summarized by Preisendorfer (1986) in ten laws (e.g. optical state of water surface, reflected sky luminance, water body reflectance, sun altitude). These factors lead to a spread in $\Gamma$ values $(6.92-9.30)$, as seen in table $1 \mathrm{~b}$ and Fig. $4 \mathrm{a}$, which correspond well to literature data $(\Gamma=8.7$ in Tyler, $1968 ; 9.5$ in Davies-Colley, 1988). This inverse relationship between $z_{\mathrm{sd}}$ and the apparent property $K_{\mathrm{k}}$ is also found with the absorption coefficient $a$ (Fig. 4a, bottom), which can be predicted by $z_{\text {sd }}$ using

$$
a_{4}=0.76-0.09 \cdot z_{\text {sd }} .
$$

The good agreement of data points (Fig. 4a) with relation Eq. (27b) indicates that Secchi depth readings and instrumentally-derived optical parameters can be considered as consistent.

Koenings and Edmundson (1991) have proposed to use the $K_{\mathrm{d}} \cdot z_{\text {sd }}$ continuum as an index of loadings by turbid particulate or organic colour. They classify waterbodies (their Table 7) on the basis of $K_{\mathrm{d}} \cdot z_{\mathrm{sd}}$, the percentage of light at $z_{\mathrm{sd}}(p$, see Eq. (27b)) and $R(0)$ into "stained", "clear" and "turbid" categories. In these terms, Lake Zug falls at the boundary between stained and clear lakes, whereas Lake Lucerne can be considered as moderately turbid. 


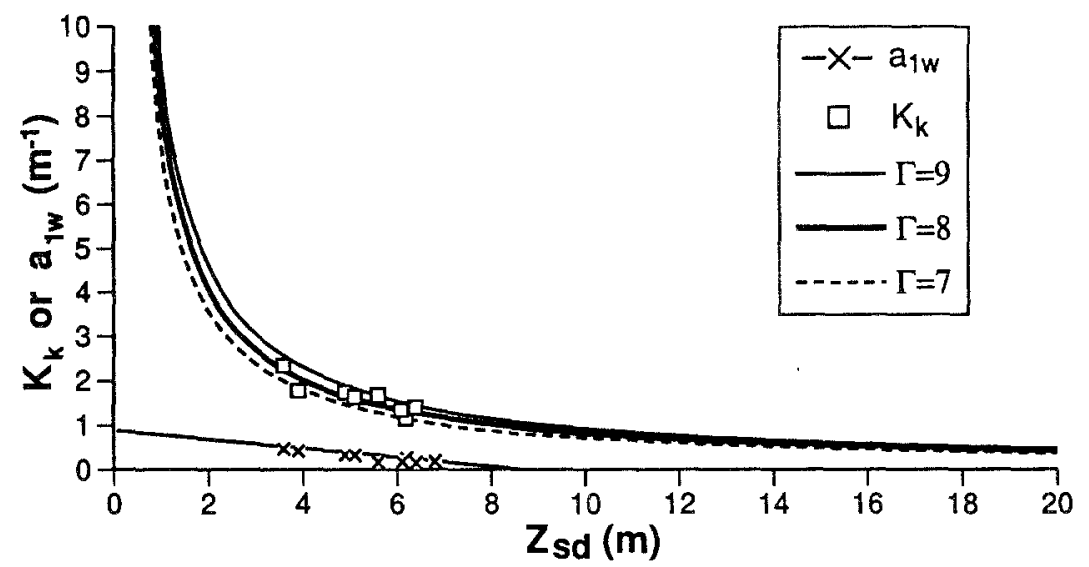

Figure 4a. Relationship between Secchi depth $\left(z_{\mathrm{sd}}\right)$ and (i) the apparent optical property $K_{\mathrm{k}}$ (theoretical equation (29a) is shown for $\Gamma=7,8$ and 9), (ii) the absorption coefficient $a_{1 \mathrm{w}}$, with adjusted equation (28)

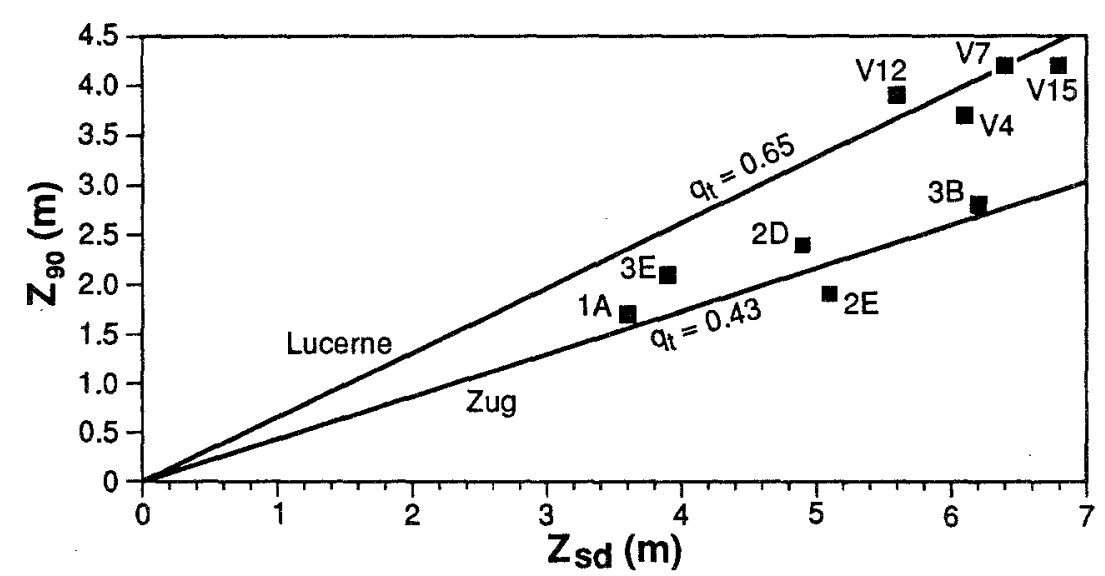

Figure 4b. Relationship between Secchi depth $\left(z_{\mathrm{sd}}\right)$ and depth of penetration of satellite signal $\left(z_{90}\right)$ for each lake. Theoretical equation (29a) is also shown for $q_{t}=0.65$ (mean value for Lake Lucerne) and $q_{\mathrm{t}}=0.43$ (mean for Lake Zug). Stations Zug: 1A - 3B. Lucerne: V4-V15

As already mentioned, the depth of penetration $z_{90}$ is an important factor for remote sensing. Two estimates are shown in Table 1a, based on in situ optical measurements. Another one could be derived from Secchi depth in the following manner: from the law of light attenuation with depth, expressed for instance by relation Eq. (2), and from Eq. (11),

$$
z_{90}^{\prime \prime}=q_{\mathrm{t}} \cdot z_{\mathrm{sd}}
$$


where

$$
q_{\mathrm{t}}=-(1 / \ln p)
$$

$p$ varies between $10 \%$ in Lake Zug ad more than $20 \%$ in Lake Lucerne (Table $1 \mathrm{~b}$ ). $q_{\mathrm{t}}$ compares well with the empirical value

$$
q_{\mathrm{r}}=z_{90} / z_{\mathrm{sd}}
$$

as shown in Fig. 4b. The variability of $p$ at Secchi depth has been discussed by Beeton (1957) for Lake Huron and Schanz (1982) for lake Zurich. Our values compare well with lake Huron average of $14.7 \%$. The reason for higher $q_{\mathrm{t}}$ values in Lake Lucerne could be explained by Preisendorfer's (1986) fourth law: the higher reflectance $R(0)$ in that lake tends to depress $z_{\text {sd }}$ readings corresponding to a given $z_{90}$, thereby increasing the slope $q_{\mathrm{t}}$ (Fig. $4 \mathrm{~b}$ ). It would be then possible to predict $z_{90}$ by Eq. (29a) in both lakes using the following empirical relation existing between $q_{\mathrm{t}}$ (Table $1 \mathrm{~b}$ ) and $R(0)$ (Table $1 \mathrm{a}$ ):

$$
q_{\mathrm{t}}^{\prime} \approx 0.35+5 \cdot R(0)
$$

which gives mean $q_{\mathrm{t}}^{\prime}$ s of 0.43 for Lake Zug (mean $R(0)=0.017$ ) and 0.65 for Lake Lucerne (mean $R(0)=0.059$ ). Koenings and Edmundson (1991) also report a dependency of $q_{\mathrm{t}}$ on $R(0)$ for Alaskan lakes, but with a different slope (1.5 vs 5 ). This difference could come from unstandardized Secchi disk type and $R$ measurements.

The vertical attenuation coefficient $K_{\mathrm{d}}$ displays additive properties, dependent upon the presence of various scattering and absorbing centres within the water column (Bukata et al. 1985). It is, therefore, possible to partition $K_{\mathrm{d}}$ into a sum of partial attenuation coefficients, the magnitude of which will cast a light on the water composition (pure water, chlorophyll, TSS and DOC).

Considering first the total suspended solid component, we have

$$
K_{\mathrm{d}}=K_{\mathrm{np}}+K_{\mathrm{p}}
$$

where $K_{\mathrm{p}}=k_{\mathrm{p}}$. TSS. $k_{\mathrm{p}}$ is the specific attenuation for total suspended solids (in $\mathrm{m}^{2}$ $\left.\mathrm{g}^{-1}\right) ; K_{\mathrm{np}}$ can be partitioned into $K_{\mathrm{w}}(0.136=$ mean over PAR of Bukata et al.'s (1985) Table 1 data) and $K_{y}$, representing the contribution of DOC. Following Smith and Baker (1978), we can rearrange Eq. (31a) as

$$
K_{\mathrm{d}}-K_{\mathrm{w}}=K_{\mathrm{y}}+k_{\mathrm{p}} \cdot \mathrm{TSS}
$$

Drawing from optical or chemical measurements of DOC, a mean estimate of $K_{\mathrm{y}}$ was derived for each lake and used as a constant when regressing $K_{\mathrm{d}}-K_{\mathrm{w}}$ on TSS. For Lake Zug $a_{3 \mathrm{u}}$ measured at $357 \mathrm{~nm}$ (Table 1a) can be used to compute that part of the absorption coefficient due to DOC and valid for PAR by applying

$$
a_{\mathrm{DOC}}(\lambda)=a_{3 \mathrm{u}} \cdot \exp (-0.014 \cdot(\lambda-357)
$$




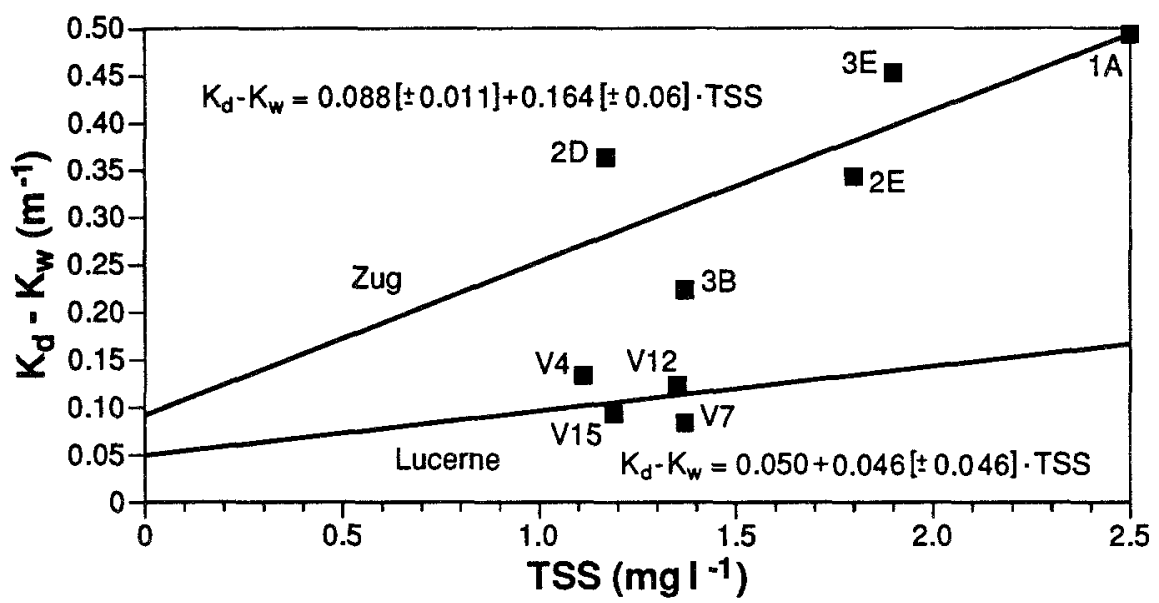

Figure 5a. Relationship between total suspended solid concentration (TSS) and corrected diffuse attenuation coefficient for downwelling irradiance $\left(K_{\mathrm{d}}-K_{\mathrm{w}}\right)$ for each lake. Linear empirical regressions (31b) were adjusted by least-square for given intercepts (TSS $=0$ ) of $K_{\mathrm{y}}=0.088 \pm$ $0.011 \mathrm{~m}^{-1}$ and slope of $0.164 \pm 0.060$ for Lake Zug, and $K_{\mathrm{y}}=0.050 \mathrm{~m}^{-1}$ and slope of $0.046 \pm 0.046$ for Lake Lucerne

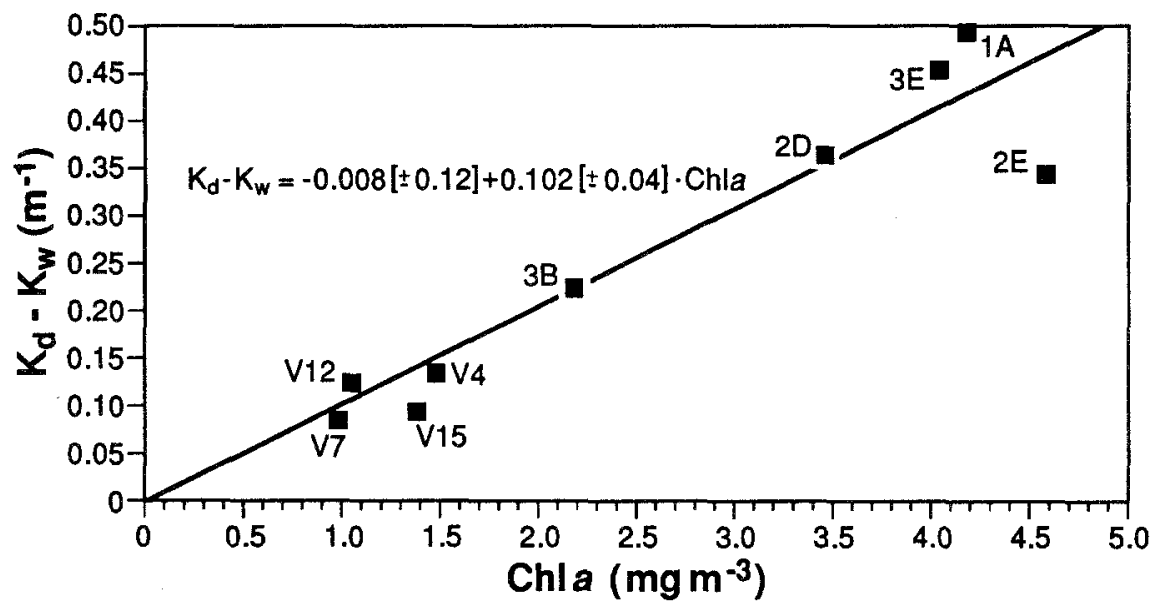

Figure 5b. Relationship between chlorophyll $a$ concentration and corrected diffuse attenuation coefficient for downwelling irradiance $\left(K_{\mathrm{d}}-K_{\mathrm{w}}\right)$ for each lake. Linear empirical regression (33d) is also shown, with intercept of $-0.008 \pm 0.120 \mathrm{~m}^{-1}$ and slope of $0.102 \pm 0.040$ 
and taking the average for $\lambda$ between 400 and $700 \mathrm{~nm}$. Thus we get $\dot{a}_{3 \mathrm{u}}=$ $0.632 \pm 0.078 \mathrm{~m}^{-1}$ and $a_{\mathrm{DOC}}=0.088 \pm 0.011 \mathrm{~m}^{-1}$, the latter being equivalent to $K_{\mathrm{y}}$. For Lake Lucerne, a survey conducted on July 1st, 1991 gave an average DOC concentration of $0.92 \pm 0.03 \mathrm{~g} \mathrm{~m}^{-3}$ over $z_{\text {sd }}$ (Bossard, unpublished). The absorption coefficient due to DOC can be then calculated from

$$
a_{\mathrm{DOC}}=\mathrm{DOC} \cdot k_{\mathrm{y}}
$$

where $k_{\mathrm{y}}$ is the specific attenuation coefficient for DOC (in $\mathrm{m}^{2} \mathrm{~g}^{-1}$ ). From Bukata et al. (1985, Table 1), $k_{\mathrm{y}}=0.0539 \mathrm{~m}^{2} \mathrm{~g}^{-1}$ for PAR interval. Hence, for Lake Lucerne, $a_{\mathrm{DOC}}=0.0500 \pm 0.0001 \mathrm{~m}^{-1}$, which is also equivalent to $K_{\mathrm{y}}$. The relation $(31 \mathrm{~b})$ is plotted separately for each lake on Fig. $5 a$, and used to determine $k_{\mathrm{p}}$ and $K_{\mathrm{p}}$ coefficients values as reported in Table 3 .

For chlorophyll (Smith and Baker 1978),

$$
K_{\mathrm{d}}=K_{\mathrm{m}}+K_{\mathrm{c}}+K_{\mathrm{z}}
$$

where the term $K_{\mathrm{m}}$ is partitioned into $K_{\mathrm{w}}$ and $K_{\mathrm{n}}$, the latter representing the contribution of substances which do not covary with Chla; $K_{\mathrm{c}}=k_{\mathrm{c}} \cdot$ Chla, $k_{\mathrm{c}}$ being the specific attenuation coefficient for chlorophyll, taken as $0.023 \mathrm{~m}^{-2} \mathrm{mg}^{-1}$ (average over PAR of case B, Bukata et al., 1985). $K_{\mathrm{z}}$ accounts for whatever components covary with Chl $a$ (POC for instance) through a proportionality factor $\alpha$ and specific attenuation coefficient $k_{z}$ such as

$$
K_{\mathrm{z}}=k_{\mathrm{z}} \cdot \alpha \cdot \operatorname{Chl} a
$$

Combining Eq. (33a and b),

$$
K_{\mathrm{d}}-K_{\mathrm{w}}=K_{\mathrm{n}}+k_{\mathrm{cc}} \cdot \mathrm{Chla}
$$

where $k_{\mathrm{cc}}=k_{\mathrm{c}}+\alpha \cdot k_{\mathrm{z}}$. The $k_{\mathrm{cc}}$ coefficient $(0.102 \pm 0.040)$ has been determined by linear regression using Eq. (33c) on both lakes taken together (Fig. 5b), and a statistical test (Krumbein and Graybill, 1965, p. 231) shows that the intercept $K_{\mathrm{n}}$ is not significant different from $K_{\mathrm{y}}$ (Zug: $0.088 \pm 0.011$; Lucerne: $0.050 \mathrm{~m}^{-1}$ ) at a $5 \%$ level, so that it is reasonable to set $K_{\mathrm{n}} \approx K_{\mathrm{y}}$. Eq. (33c) then becomes

$$
K_{\mathrm{d}}-K_{\mathrm{w}}=K_{\mathrm{y}}+K_{\mathrm{cc}}
$$

with $K_{\mathrm{cc}}=k_{\mathrm{cc}} \cdot$ Chla. The last unknown term $\alpha \cdot k_{\mathrm{z}}$ is computed by difference $\left(k_{\mathrm{cc}}-\right.$ $k_{\mathrm{c}}=0.079 \pm 0.040 \mathrm{~m}^{-1}$ ). Finally, by combining Eq. (31b) and Eq. (33d), we get the following identity, coupling the suspended solid and chlorophyll systems:

$$
k_{\mathrm{p}} \cdot \mathrm{TSS}=k_{\mathrm{cc}} \cdot \mathrm{Chl} a
$$

or

$$
K_{\mathrm{p}}=K_{\mathrm{cc}}
$$


Table 3. Contribution of partial attenuation coefficients (boldface) to the total attenuation coefficient $K_{\mathrm{d}}$ as computed for the TSS (top) and Chl $a$ components (bottom)

\begin{tabular}{|c|c|c|c|c|c|c|c|c|c|c|c|}
\hline \multirow{2}{*}{$\begin{array}{c}\text { TSS } \\
\mathrm{Zug}\end{array}$} & \multirow{4}{*}{$\begin{array}{l}\text { Mean } \\
\text { Range }\end{array}$} & \multirow{2}{*}{$\begin{array}{l}\boldsymbol{K}_{\mathrm{w}}^{\mathrm{a}} \\
\mathbf{0 . 1 3 6}\end{array}$} & \multirow{2}{*}{$\frac{\boldsymbol{K}_{\mathrm{y}}^{\mathrm{b}}}{\mathbf{0 . 0 8 8}}$} & \multirow{2}{*}{$\begin{array}{l}k_{\mathrm{y}}^{\mathrm{a}} \\
0.054\end{array}$} & \multicolumn{3}{|c|}{$\begin{array}{l}K_{\mathrm{np}}^{\mathrm{e}} \\
\mathrm{K}_{\mathrm{w}}+\mathrm{K}_{\mathrm{y}}\end{array}$} & \multirow{2}{*}{$\begin{array}{l}k_{\mathrm{p}}^{\mathrm{c}} \\
0.164\end{array}$} & \multirow{2}{*}{$\begin{array}{c}\boldsymbol{K}_{\mathrm{p}}^{\mathrm{d}} \\
\mathbf{0 . 2 8 7}\end{array}$} & \multirow{2}{*}{$\frac{K_{\mathrm{d}}^{2}}{0.51}$} & \multirow{2}{*}{$\frac{\boldsymbol{K}_{\mathrm{d}}^{6}}{\mathbf{0 . 5 1}}$} \\
\hline & & & & & 0.224 & & & & & & \\
\hline & & - & 0.077 & - & 0.213 & & & 0.104 & 0.115 & 0.33 & 0.38 \\
\hline & & & 0.099 & & 0.235 & & & 0.224 & 0.535 & 0.77 & 0.64 \\
\hline \multirow[t]{3}{*}{ Lucerne } & Mean & 0.136 & 0.050 & 0.054 & 0.186 & & & 0.046 & 0.058 & 0.24 & 0.24 \\
\hline & Range $^{5}$ & - & - & - & - & & & & & 0.19 & 0.21 \\
\hline & & & & & & & & 0.092 & 0.132 & 0.32 & 0.27 \\
\hline Chla & & $\boldsymbol{K}_{\mathrm{w}}^{\mathrm{a}}$ & $\boldsymbol{K}_{\mathrm{n}}^{\mathrm{b} 4}$ & $k_{c}^{\mathrm{a} 1}$ & $K_{\mathrm{c}}^{\mathrm{d}}$ & $\alpha \cdot k_{z}$ & $K_{z}^{\mathrm{d}}$ & $k_{\mathrm{cc}}^{\mathrm{c}}$ & $\boldsymbol{K}_{\mathrm{cc}}^{\mathrm{d}}$ & $K_{\mathrm{d}}^{3}$ & $\boldsymbol{K}_{\mathrm{d}}^{6}$ \\
\hline \multirow[t]{3}{*}{ Zug } & Mean & 0.136 & 0.088 & 0.023 & 0.085 & 0.079 & 0.292 & 0.102 & 0.376 & 0.60 & 0.51 \\
\hline & Range & - & 0.077 & - & 0.058 & 0.039 & 0.099 & 0.062 & 0.157 & 0.37 & 0.38 \\
\hline & & & 0.099 & & 0.116 & 0.119 & 0.577 & 0.142 & 0.689 & 0.92 & 0.64 \\
\hline \multirow[t]{3}{*}{ Lucerne } & Mean & 0.136 & 0.050 & 0.023 & 0.028 & 0.079 & 0.096 & 0.102 & 0.124 & 0.31 & 0.24 \\
\hline & Range & - & - & - & 0.021 & 0.039 & 0.036 & 0.062 & 0.057 & 0.24 & 0.21 \\
\hline & & & & & 0.035 & 0.119 & 0.181 & 0.142 & 0.216 & 0.40 & 0.27 \\
\hline
\end{tabular}

: Value corresponding to case B of Bukata et al (1985, Fig. 46), and appropriate for phytoplankton population dominated by chlorophyta (Schanz, 1985)

${ }^{2}$ Sum of $K_{\mathrm{w}}+K_{\mathrm{y}}+K_{\mathrm{p}}$

${ }^{3}$ Sum of $K_{\mathrm{w}}+K_{\mathrm{cc}}$

${ }^{4} \mathrm{~K}_{\mathrm{n}}=-0.008$, falling within confidence limits of $K_{\mathrm{y}}$, hence taken as approximately equivalent to mean $K_{y}$

${ }^{5}$ As mean \pm confidence interval ( 0.05 level)

${ }^{6}$ From Table 1a

${ }^{a}$ From literature data

${ }^{b}$ From measurements

c From statistical regression

${ }^{\mathrm{d}}$ Computed from mean values for Chla and TSS (Table 1b)

e Computed arithmetically

In Table $3, K_{\mathrm{p}}$ and $K_{\mathrm{cc}}$ show a large dispersion about their mean, resulting from the accumulated uncertainty affecting most of the coefficients. Since the ranges do overlap to a fair extent (for instance, in Lake Zug, $K_{\mathrm{p}}$ and $K_{\mathrm{cc}}$ ranges are $0.115-$ 0.535 , and $0.157-0.689$, respectively, with means of 0.287 and 0.376 ), one can consider the components of vertical attenuation $K_{\mathrm{w}}, K_{\mathrm{y}}, K_{\mathrm{p}}$ and $K_{\mathrm{cc}}$ to provide, at this preliminary stage, order-of-magnitude information.

In Lake Zug, $K_{\mathrm{p}}$ is an important component of $K_{\mathrm{d}}$, which is not the case in Lake Lucerne, in spite of similar concentrations in total suspended solids $(1.75 \mathrm{vs} 1.26 \mathrm{mg}$ $1^{-1}$, Table $1 b$ ). This can be ascribed to a marked contrast in the particle specific attenuation coefficient $\left(k_{\mathrm{p}}\right)$ values which are, in Lake Zug, close to that reported by Bukata et al. (1985, Table 1; mean over PAR values: $0.138 \mathrm{~m}^{-1}$ ), and much lower in 


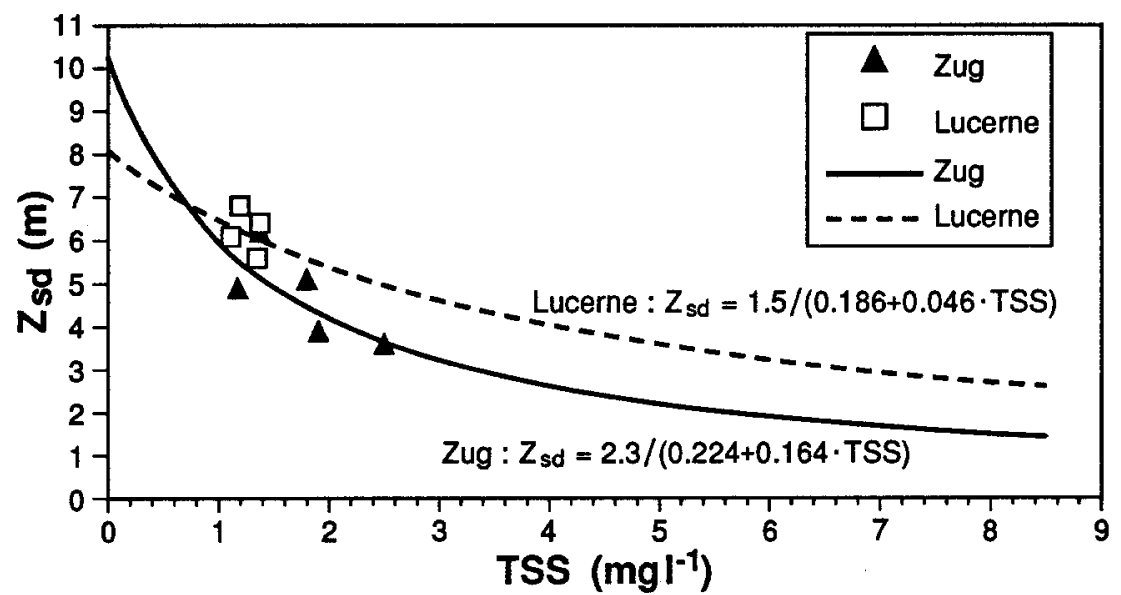

Figure 6. Relationships between Secchi depth $\left(z_{\mathrm{sd}}\right)$ and total suspended solids (TSS). The curves represent the combination of theoretical equations (35) and (31b)

Lake Lucerne. This low efficiency of Lake Lucerne suspensoids in vertical attenuation of light would have to be confirmed, and explained, by investigations on particle typology, optical properties and grain-size. As a consequence, Secchi depth readings taken in Lake Lucerne should not be expected to react proportionately to large variations in total suspended solid concentration, which is demonstated in Fig. 6 (slope of curve steeper in Lake Zug than in Lake Lucerne). This is also shown in the following relation, obtained by combining Lorenzen's (1980) relation and Eq. (29b)

$$
z_{\mathrm{sd}} \approx\left(1 / q_{\mathrm{t}}\right) / K_{\mathrm{d}}
$$

where $K_{d}$ is expressed as function of TSS by Eq. (31b).

The impact of dissolved organic carbon on $K_{\mathrm{d}}$, as indicated by $K_{\mathrm{y}}$, is also smaller in Lake Lucerne than in Lake Zug, which might be expected because of its oligotrophic state. However, in Lake Lucerne, $K_{\mathrm{y}}$ is of the same order of magnitude as $K_{\mathrm{p}}\left(0.050 \mathrm{vs} 0.058 \mathrm{~m}^{-1}\right)$, and about half the level of $K_{\mathrm{w}}$. Because of the low efficiency of particles in attenuating light, DOC then becomes a relatively important factor in the optical properties of Lake Lucerne.

Higher chlorophyll levels in Lake Zug are reflected in larger $K_{\mathrm{cc}}$ values $(0.376 \mathrm{vs}$ $\left.0.124 \mathrm{~m}^{-1}\right)$. Based on a likely specific absorption coefficient value for chlorophyll $\left(k_{c}=0.023 \mathrm{~m}^{2} \mathrm{mg}^{-1}\right.$; see Table 3, note 1$)$, and on a regressed $k_{\mathrm{cc}}$ of $0.102 \pm 0.04 \mathrm{~m}^{2}$ $\mathrm{mg}^{-1}$, the $\alpha \cdot k_{\mathrm{z}}$ coefficient was found to be relatively high $\left(0.079 \mathrm{~m}^{2} \mathrm{mg}^{-1}\right)$. This could indicate that, in Lake Zug, Chla-covarying material ("non-living organic component" of Bukata et al., 1981a, or seston) has a stronger impact on vertical light attenuation than chlorophyll itself. 


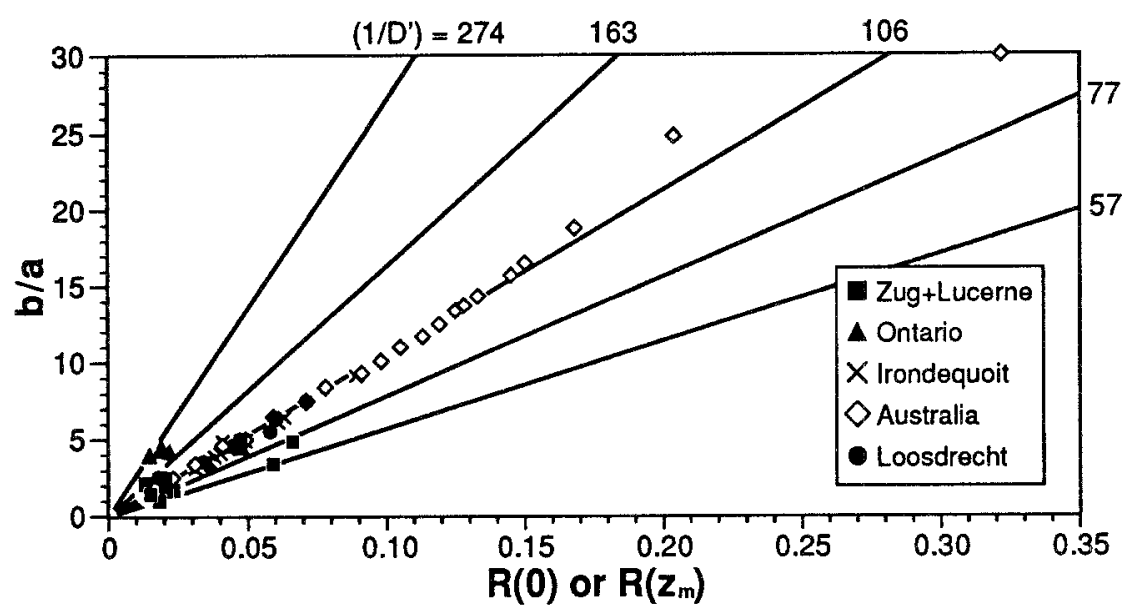

Figure 7. Relationship of scattering to absorption ratio $(b / a)$ with vector irradiance reflectance $R$ at $0 \mathrm{~m}$ for Lakes Zug and Lucerne or $R$ at mid-euphotic depth $\left(z_{\mathrm{m}}\right)$ for selected waterbodies. Theoretical equation $(10 \mathrm{a})$ is shown for $\left(1 / D^{\prime}\right)$ values between 57 and 274

\subsection{Estimation of b/a from $R(0)$}

The relation between the ratio of $\left(b_{3 \mathrm{w}} / \alpha_{1 \mathrm{w}}\right)$ and $R(0)$ is plotted on Fig. 7 for lakes Zug and Lucerne, together with data from other water bodies: Irondequoit Bay (Weidemann and Bannister, 1986), Lake Ontario in June 1977 (Bukata et al., 1979), turbid Australian lakes (Kirk 1981) and Loosdrecht lakes system in Holland (Dekker et al., 1992). Also shown are the values taken by the proportionality factor $\left(1 / D^{\prime}\right)_{\mathrm{c}}$ (Table 1a), computed after Eq. (10a). In our lakes and lake Ontario, irradiance reflectance is taken immediately below the surface, whereas it is considered at $z_{\mathrm{m}}$ in the other water bodies.

In Lake Ontario, $\left(1 / D_{c}^{\prime}\right)$ varies widely from 274 at pelagic station 12 to 94 near the coast, due to a variation of the back-scattering probability $B(0.011$ to 0.033 ; Table 1a). The spread in $\left(1 / D_{c}^{\prime}\right)$ goes from $58(\mathrm{~V} 4)$ to $160(2 \mathrm{E})$ in our lakes, and reduces to $57-100$, if the somewhat anomalous station $2 \mathrm{E}$ is excluded, making reasonable the consideration of an average value of 77 valid for both lakes. For the other water bodies considered in Fig. $7,\left(1 / D_{c}^{\prime}\right)$ is practically invariant between $100-110$, only because $B$ is considered as constant and equal to 0.019 (value taken from San Diego Harbour, Kirk 1981). Therefore, the predictability of $b / a$ from remotely-sensed $R(0)$ will depend on the knowledge of $B$, which is still quite poor. At this stage, it is only possible to globally discriminate Lake Zug from Lake Lucerne on the basis of the PAR scattering to absorption ratio by using $R(0)$ measured in situ: the mean value of the ratio is $1.59 \pm 0.49$ in Lake Zug, significantly lower ( 0.01 level) than $4.30 \pm 1.25$ in Lake Lucerne.

The $a$ and $b$ coefficients provide a convenient way to display the overall optical properties of water bodies, as shown by Weidemann and Bannister (1986), and shown in Fig. 8. Lake Lucerne has an absorption level $\left(a_{1 w}=0.187 \pm 0.014\right)$ lower 


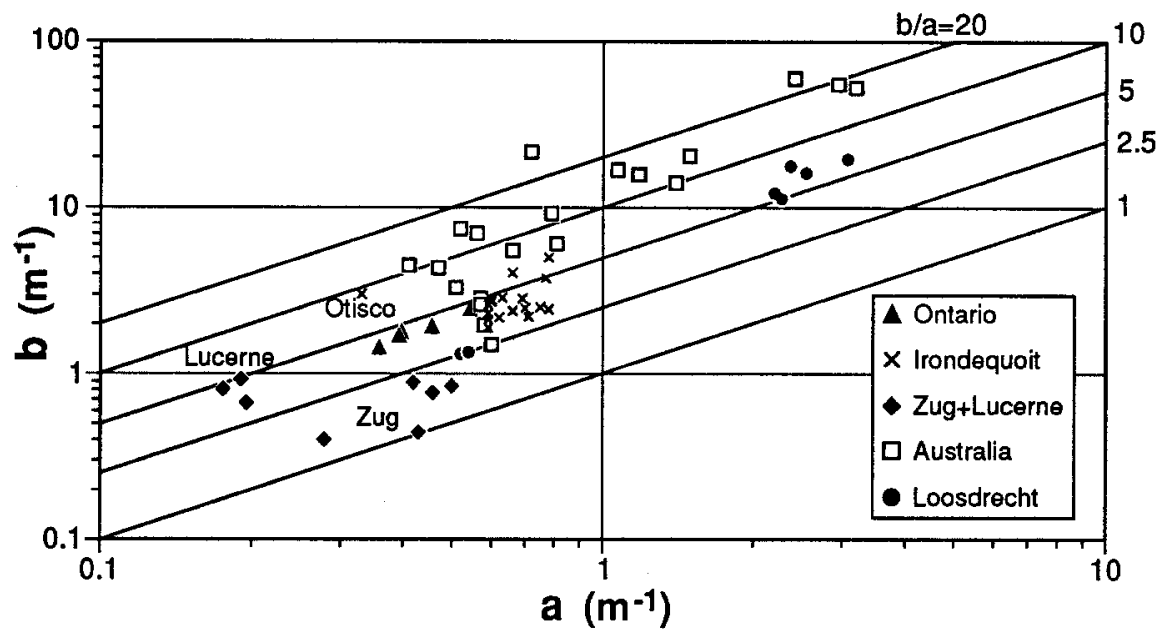

Figure 8. Position of Lakes Zug and Lucerne in the absorption (a) vs. scattering continuum $(b)$. Selected waterbodies are included for comparison

than all the other water bodies considered, but its $b / a$ ratio is similar to that of Lake Ontario and Irondequoit Bay. The latter shows a logical increase in $b / a$ towards Summer (Weidemann and Bannister, 1986). The large $b / a$ ratio in Lake Otisco (Fig. 8) is due to the presence of precipitated $\mathrm{CaCO}_{3}$ (Weidemann et al. 1985), in strong contrast to Lake Zug, where organic sestonic particles had a lower scattering efficiency at the date of sampling.

\subsection{Spectral in-water measurements and water colour}

Up and downwelling spectral irradiance is available from stations $2 \mathrm{E}, 3 \mathrm{~B}, 3 \mathrm{E}$ ( $\mathrm{Zug}$ ) and V4, V15 (Lucerne), making possible the computation of irradiance reflectance spectra, shown on Fig. 3a for the surface layer. Although the spectra from Lake Lucerne are noisy (surface waves), the contrast in optical character is obvious between both lakes.

In order to compare the spectral measurements with PAR data $(R(0))$, narrowband readings were aggregated into the $400-700 \mathrm{~nm}$ interval $\left(R^{\prime \prime}(0)\right)$, as well as into the TM bands $\left(R^{\prime \prime \prime}(0)\right)$ using Eq. (16) and Eq. (15). These values are shown on Fig. 3b (stn. 3E as example) and in Table 2 . Narrow-band chromaticity coordinates $\{x, y, z\}$ were calculated from up and downwelling spectral irradiance, following the methodology outlined above. They are also given in Table 2 .

Water colour information can be gained in a number of ways. A first, simple index of colour is given by the ratio $R_{\mathrm{e} 1} / R_{\mathrm{e} 2}$, as seen in Table 2 and on the histograms of Fig. 9. There are some heterogeneities in this "blue"/green ratio within Lake Zug (stn. 1B: 0.29; stn. 1A: 0.65), and a distinct difference to Lake Lucerne, the water of which appears to be bluer (ratio $\geq 1)$. 

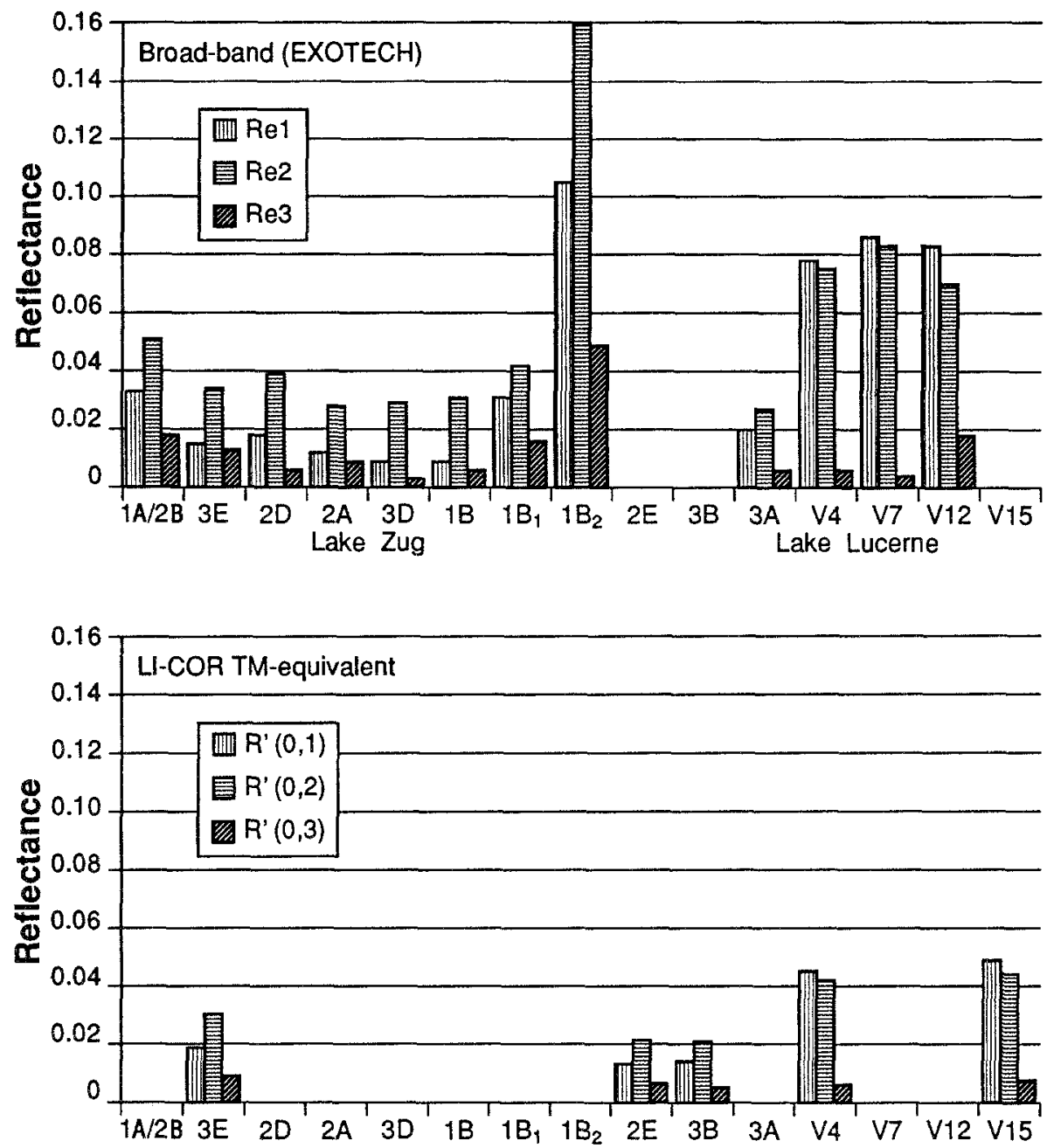

Figure 9. Comparison of (a) Broad-band EXOTECH reflectance spectra collected above surface with (b) TM-equivalent reflectance spectra (from underwater LI-COR measurements)

This trend is confirmed by a visual inspection of the high-resolution spectra (Fig. 3a), showing higher reflectances reaching a plateau between 500 and $560 \mathrm{~nm}$ for Lake Lucerne, in contrast to lower and narrower peaks (around $550 \mathrm{~nm}$ ) for Lake Zug. A noise component induced by winddriven wavelets is also visible in Lake Lucerne spectra, as well as a slight trough, which could be due to the absorption band of chlorophyll at 675-680 (Dekker et al. 1991), or maybe to a subsequent peak near $685 \mathrm{~nm}$ : Gitelson (1992) has shown that the peak position shifts from $684 \mathrm{~nm}$ to $710 \mathrm{~nm}$ with increasing Chla concentration. For station $3 \mathrm{E}$, the position at $685-690 \mathrm{~nm}$ corresponds well to the Chla level of $4.04 \mathrm{mg} \mathrm{m}^{-3}$ (Table 1b). 


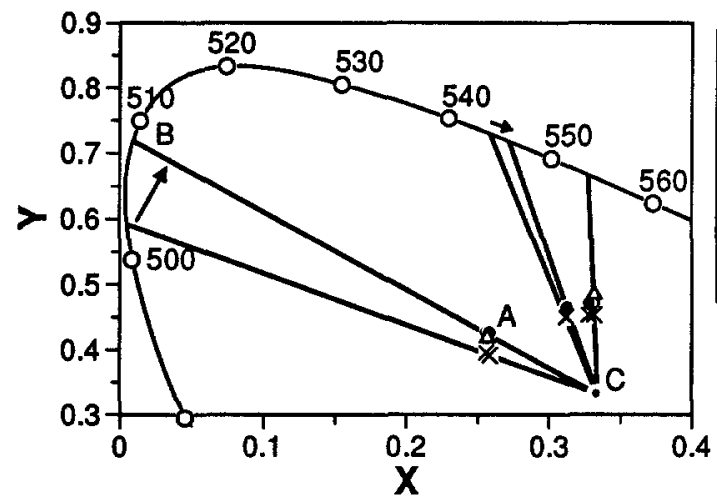

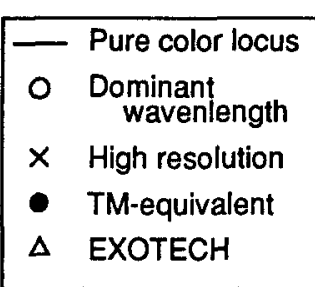

Saturation is given by $[\mathrm{CA}] /[\mathrm{CB}]$

Figure 10a. Chromaticity diagram comparing "true" colour estimates by narrow-band LI-COR, TM-equivalent (from LI-COR) and broad-band EXOTECH radiance measurements. Dominant wavelengths are given between 500 and $550 \mathrm{~nm}$. "C" is the achromatic point. Segments CA and CB are used to compute colour saturation. Arrows indicate the shift in dominant wavelength or hue induced by using broad-band TM-equivalent spectra

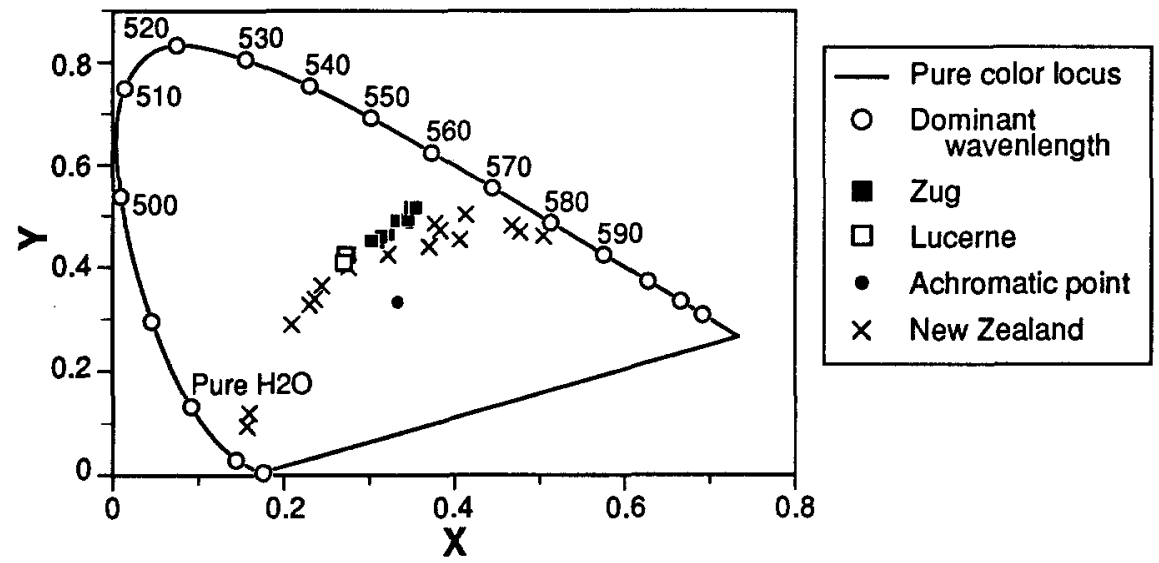

Figure 10b. Colour characteristics (hue and saturation) of Lakes Zug and Lucerne as shown on the chromaticity diagram, and compared to a suite of New Zealand waterbodies (Davies-Colley et al., 1988)

A more synthetic expression of colour is given by chromaticity (Jerlov 1968, Smith et al. 1973, Alföldi and Munday 1978, Jaquet and Zand 1989), as demonstrated in Fig. 10b for EXOTECH-derived measurements (Table $3, R_{\mathrm{ei}}$ ). Keeping in mind the slight overestimation in $y$ already mentioned, lakes Lucerne and Zug fall approximately on the same locus as a set of New Zealand waterbodies reported by Davies-Colley et al. (1988). Lucerne has a dominant wavelength (or hue) around $510 \mathrm{~nm}$ (blue-green) with a low saturation $(\mathrm{S}=0.2$, due to the flatness of the spectra; Fig. 3a), and Zug ranges between $540 \mathrm{~nm}(\mathrm{~S}=0.29$; green $)$ and $560(\mathrm{~S}=0.62$, green-yellow). 
Table 4. Summary of bio-optical characteristics (ranges of values). $R_{\max }$ : maximum value of spectral reflectance. $\lambda_{\text {dom }}$ : dominant wavelength from chromaticity diagram. S: saturation from chromaticity diagram. SM: Suspended Matter concentration ( $\left.\mathrm{mg} \mathrm{l}^{-1}\right)$. DOC: Dissolved Organic Carbon concentration $\left(\mathrm{mg} \mathrm{l}^{-1}\right)$

\begin{tabular}{|c|c|c|c|c|c|c|c|c|c|c|c|}
\hline Lake & $z_{\mathrm{sd}}$ & $a_{\mathrm{PAR}}$ & $b_{\mathrm{PAR}}$ & $\begin{array}{l}b / a \\
\text { PAR }\end{array}$ & $R_{\max }$ & $\lambda_{\text {diom }}$ & $\mathrm{S}$ & Chla & SM & $\mathrm{DOC}$ & $\begin{array}{l}\text { Trophic } \\
\text { level } \\
\text { Reference }\end{array}$ \\
\hline & $\mathrm{m}$ & $\mathrm{m}^{-1}$ & $\mathrm{~m}^{-1}$ & & & $\mathrm{~nm}$ & & $\mu \mathrm{g} \mathrm{I}^{-1}$ & $\mathrm{mg} \mathrm{l}^{-1}$ & $\mathrm{mg} \mathrm{l}^{-1}$ & \\
\hline Zug & $\begin{array}{l}3.6 \\
6.2^{1}\end{array}$ & $\begin{array}{l}0.28 \\
0.50\end{array}$ & $\begin{array}{l}0.40 \\
0.89\end{array}$ & $\begin{array}{l}1.03 \\
2.12\end{array}$ & $\begin{array}{l}0.024 \\
0.032\end{array}$ & $\begin{array}{l}540 \\
560\end{array}$ & $\begin{array}{l}0.29 \\
0.62\end{array}$ & $\begin{array}{l}2.2 \\
4.6\end{array}$ & $\begin{array}{l}1.2^{2} \\
2.5\end{array}$ & $?$ & $\begin{array}{l}\mathrm{E} \\
\text { This work }\end{array}$ \\
\hline Lucerne & $\begin{array}{l}5.6 \\
6.8\end{array}$ & $\begin{array}{l}0.18 \\
0.20\end{array}$ & $\begin{array}{l}0.67 \\
0.93\end{array}$ & $\begin{array}{l}3.4 \\
4.9\end{array}$ & $\begin{array}{l}0.045 \\
0.055\end{array}$ & $\begin{array}{l}510 \\
514\end{array}$ & $\begin{array}{l}0.20 \\
-\end{array}$ & $\begin{array}{l}1.0 \\
1.5\end{array}$ & $\begin{array}{l}1.1^{2} \\
1.4\end{array}$ & $0.9^{5}$ & $\begin{array}{l}\text { M } \\
\text { This work }\end{array}$ \\
\hline Ontario ${ }^{4}$ & 2.3 & 0.46 & 1.9 & 4.2 & 0.033 & 570 & - & - & - & - & $\begin{array}{l}\text { M } \\
\text { Bukata } \\
\text { et al. 1979, } \\
88,91\end{array}$ \\
\hline Tikitapu & 7.8 & - & - & - & 0.049 & 495 & 0.27 & 0.8 & 0.4 & - & $\begin{array}{l}\text { O } \\
\text { Davies- } \\
\text { Colley et al. } \\
(1988)\end{array}$ \\
\hline $\begin{array}{l}\text { Waikare- } \\
\text { moana }\end{array}$ & 20 & - & - & - & 0.013 & 500 & 0.23 & 0.6 & 0.2 & - & $\begin{array}{l}\text { O } \\
\text { Ibidem }\end{array}$ \\
\hline Rotokakahi & 8.3 & - & - & - & 0.018 & 525 & 0.18 & - & - & - & $\begin{array}{l}\text { O } \\
\text { Ibidem }\end{array}$ \\
\hline Ohakuri & 3.4 & - & - & - & 0.028 & 556 & 0.33 & - & - & - & $\begin{array}{l}\text { O } \\
\text { Ibidem }\end{array}$ \\
\hline $\begin{array}{l}\text { Adiron- } \\
\text { dack } 2\end{array}$ & - & - & - & - & $\begin{array}{l}0.01 \\
0.04\end{array}$ & $\begin{array}{l}500 \\
580\end{array}$ & - & $\begin{array}{l}- \\
-\end{array}$ & - & - & $\begin{array}{l}? \\
\text { Vertucci \& } \\
\text { Likens } \\
(1989)\end{array}$ \\
\hline $\begin{array}{l}\text { Adiron- } \\
\text { dack } 3\end{array}$ & - & - & - & - & $\begin{array}{l}0.01 \\
0.02\end{array}$ & $\begin{array}{l}550 \\
575\end{array}$ & - & $\begin{array}{l}1.0 \\
2.1\end{array}$ & $\begin{array}{l}0.1^{3} \\
0.4^{3}\end{array}$ & $\begin{array}{l}2.3 \\
2.6\end{array}$ & $\begin{array}{l}? \\
\text { Ibidem }\end{array}$ \\
\hline
\end{tabular}

O: oligotrophic. M: mesotrophic. E: eutrophic.

${ }^{1}$ Range of values

${ }^{2}$ As Total Suspended Solids

${ }^{3} \mathrm{As} \mathrm{SiO}_{2}$

${ }^{4}$ St 1, May 1977. $z_{\text {sd }}$ computed from Bukata et al.'s (1988) regression

${ }^{5}$ Mean over Secchi depth of several stations on July 1st, 1991 
The overall bio-optical characteristics of our lakes for the sampling date are summarized in table 4, together with selected literature data for comparative purpose. Lakes Zug and Lucerne show analogies with types 2 and 3 of Vertucci and Likens' (1989) classification of Adirondack lakes (similar spectral shape, dominant wavelength and chlorophyll content). When compared to New Zealand waterbodies (Davies-Colley et al., 1988) on the basis of chromaticity, Lake Lucerne is close to Rotokakahi (mesotrophic), and Zug to Ohakuri (meso/eutrophic), but with somewhat higher chlorophyll values. Owing to the optical complexity of inland waters, one can expect the various typologies not to be equivalent. Indeed, in their critical evaluation of the chromaticity method, Bukata et al. (1983) have shown by optochemical modelling that there is no unequivocal correspondence between colour and biochemical water composition.

The question that remains to be addressed is how exactly can the trophic state or quality of a water body be retrieved from optical or colour measurements, provided this operation is conducted in a reasonably well-known limnological context.

\subsection{Broad-band, above-water measurements}

Downwelling irradiance and upwelling above-water radiance was measured by EXOTECH spectrometer at 10 stations in 3 visible bands similar to those of Thematic Mapper. This type of data is intermediate between in-water and airborne/ satellite-derived information. Irradiance reflectance in the visible bands $\left(R_{\mathrm{e} 1}, R_{\mathrm{e} 2}\right.$, $\left.R_{\mathrm{e} 3}\right)$ and for their sum $\left(R_{\mathrm{ex}}\right)$ are shown in Table 2 , as well as the simple ratio $R_{\mathrm{e} 1} / R_{\mathrm{e} 2}$, approximately equivalent to a blue/green ratio.

Although the first three bands of TM do not span the whole visible region $(450-690 \mathrm{~nm}$, with a gap between 600 and 630 , versus $400-700 \mathrm{~nm}$; see Fig. 3b), we have computed approximate chromaticity coordinates as indicated above. These have to be distinguished from the satellite-TM chromaticity given in the literature (see for instance Alföldi and Munday, 1978, or Jaquet and Zand 1989), wherein $x, y$ and $z$ are merely ratios of the kind: \{radiance of $i$ band $\} /\{$ sum of bands 1 to 3 \}. Approximate chromaticity values are given in table 2 for underwater LI-COR TMequivalent spectra $\left\{x_{t}, y_{t}, z_{t}\right\}$ and above-water, broad-band (EXOTECH) spectra $\left\{x_{\mathrm{e}}, y_{\mathrm{e}}, z_{\mathrm{e}}\right\}$.

\section{Discussion}

\subsection{Methodological validity of $a, b$ and $c$ estimates $(P A R)$}

The computation of absorption coefficient $a_{1}$ from Eq. (8) is theoretically sound at any depth (Zaneveld, 1989), and averaging over $z_{90}$ should attenuate the noise due to changes in irradiance. The $a_{1}$ values shown in Table 1a also exhibit a distinct trend in Lake $\mathrm{Zug}\left(0.5 \mathrm{~m}^{-1}\right.$ at northernmost, eutrophic station $1 \mathrm{~A}$, and decreasing towards the south), and are clearly lower in oligotrophic Lake Lucerne $\left(<0.2 \mathrm{~m}^{-1}\right)$. 
It is interesting to compare $a_{1}$ (PAR) with $a_{3}$, obtained from laboratory measurements on filtered water at $357 \mathrm{~nm}$ (near UV): the latter is $50 \%$ higher, which can be explained by the general shape of the absorption coefficient spectrum with respect to wavelength, decreasing in amplitude from UV towards the visible (see for example absorption spectra shown by Bowling et al., 1986, Fig. 7). The mean value of $\alpha_{3}$ in Lake Zug $\left(0.63 \mathrm{~m}^{-1}\right)$ compares well with ranges reported by Bricaud et al. (1981) for the eutrophic Etang de Fos-Berre, and by Bowling et al. (1986) for Tasmanian "clear" waters.

Total scattering coefficient was estimated by nephelometry ( $\mathrm{Zug}$ ) and by difference between $c_{2}$ and $a_{1}$ (Lucerne), and computed from $\mu(0), K_{\mathrm{d}}$ and $a_{1}$ (relation Eq. (6)). Under optimal conditions, turbidity values measured as FTU's are reported to be, within a few percent, equivalent to $b$ (Weidemann and Bannister, 1986). In Lake Zug, the nephelometer used was not sheltered from ambient light, so that the near-surface measurements of $b_{3}$ are expected to be somewhat underestimated (Nyffeler, oral comm.). In Lake Lucerne, $b_{4}$ obviously also includes the inaccuracy attached to $c_{2}$ and $\alpha_{1}$. Finally, the estimation of $b_{2}$ made using Kirk's (1991) formula should be used with caution: the non-homogeneity of the water-column properties is suspected to introduce a serious error in the estimation (Weidemann and Bannister, 1986).

Beam attenuation coefficient estimated as $c_{l}$ is, in Lake Zug, close to, or smaller than $a_{1}$. Downwelling light contamination in water is unlikely, since the beam is sheltered in a pipe, but backscattered upwelling light near the surface could induce an underestimation of $c_{1}$ by increasing transmissivity (see Eq. (20)). The measures in air could be underestimated because of the so-called "window effect" (Nyffeler, oral comm.). Another reason to support an underestimation of $c_{1}$ is given by the fact that the ratio $\mathrm{TSS} / c_{1}$ is 5 vs 1.7 for $\mathrm{TSS} / c_{3}$. The latter is closer to literature values (2.5, Di Toro 1978; Bapst 1987). In Lake Lucerne, $c_{2}$ is always larger than $a_{1}$.

The differences between depth-weighted and unweighted estimates over $z_{90}$ are within a few percents for $a$, and larger for $b$. For the reasons mentioned above, we will, therefore, consider the depth-weighted means $\alpha_{1 \mathrm{w}}, b_{3 \mathrm{w}}, b_{4 \mathrm{w}}$ and $c_{3 \mathrm{w}}$ as firstapproximation estimates of the inherent optical properties of the surface layer within reach of remote sensing investigations.

\subsection{Representativity of broad-band, above-water measurements}

The spectra measured a few decimeters above water by EXOTECH spectrometer are intermediate between the in situ information collected just below the interface (Fig. 3a), and the data that could be provided by the AVIRIS or satellite spectrometers. A complete set of these surface reflectance spectra were available, so we can first evaluate how representative they are with respect to the high-resolution data provided by the LI-COR $1800 U W$. For comparison, the high-resolution spectra were aggregated into the three TM-equivalent intervals in the visible $\left(R^{\prime}(0, \mathrm{i})\right.$ in Table 2), and are plotted with EXOTECH spectra $\left(R_{\mathrm{ei}}\right)$ on Fig. 9.

No exact relationship can be derived from this limited data set, but the agreement between both types of measurement is reasonable. In particular, the 
reflectance contrast between lakes Zug and Lucerne is also evident from broadband data, as well as the difference in the blue/green ratio $\left(R_{\mathrm{e} 1} / R_{\mathrm{e} 2}\right.$, Table 2$)$.

The possible degrading effect of increased band-width and lack of true blue band in TM-type sensors on chromaticity values has also been investigated by comparing narow-band, true chromaticity to TM-equivalent estimates. The results are shown on the $x$ vs. $y$ chromaticity diagram of Fig. 10a, and in Table 2 . With respect to true values (LI-COR-derived), TM-equivalents $y^{\prime}$ s are higher $(0.02-0.04), x^{\prime} \mathrm{s}$ are similar and $z$ 's are lower. This is understandable on the grounds that TM band 1 is centered at $485 \mathrm{~nm}$, well in the blue-green, which then overestimates the "greenness" expressed by $y$.

Depending on the position of the water parcels with respect to the achromatic point $\mathrm{C}$, the overstimation of $y$ by EXOTECH will have the following effects (Fig. 9a):

- A $5 \mathrm{~nm}$ increase of the dominant wavelength for Lake Lucerne, located between $500-510 \mathrm{~nm}$, without any change in saturation.

- A $2 \mathrm{~nm}$ increase of the dominant wavelength for station 3B in Lake Zug $(546 \mathrm{~nm})$, with a increase in saturation of 0.05 .

- No change in the dominant wavelenght for stations $2 \mathrm{E}$ and $3 \mathrm{E}(552-555 \mathrm{~nm})$, but an increase in saturation of 0.08 .

Therefore it would be possible to correct the colour parameters estimated on the basis of broad-band instruments. Work is in progress to design a correction scheme, based on a theoretical approach. For the moment, the small bias will be considered when comparisons are made with other water bodies (see below), and we can conclude that the common and relatively inexpensive instruments based on TM bandwidths do have a reasonable potential for use in water colour studies.

\subsection{Optochemical modelling}

The link between water composition and reflectance spectra can be established through an optochemical model, as proposed by Bukata et al. (1985). The magnitude of the absorption and scattering coefficients depends on the contribution of water, pigments, mineral suspensoids and dissolved organic carbon, as arithmetic products of concentration by optical cross-section (or, in other words, by specific absorption and scattering coefficients). These have been determined for lakes Ontario and Ladoga by Bukata et al. (1991a), and shown to be site-specific.

It is, therefore, possible to derive a reflectance spectrum from known concentrations of Chla, SM and DOC. Inversely, prediction of lake water composition is also possible from a reflectance spectrum (Bukata et al., 1985), provided that the appropriate cross-sections are applied.

Several reflectance spectra (not shown) were computed using various combinations of Chla, SM and DOC values, with cross-sections from Ontario or Ladoga. It was possible to simulate spectra broadly similar to those of Lake Zug (and, to a lesser extent, Lake Lucerne), but from combinations of components different from those found in our lakes. In particular, confirming Bukata et al.'s $(1985$, p. 26) and Vertucci and Likens' (1989) findings, chlorophyll and DOC had to be kept at un- 
realistically low levels to insure a satisfactory fit. This suggests that the Chla crosssections $\left(k_{\mathrm{c}}\right)$ we applied were not valied for Lake Lucerne.

\subsection{Relevance for remote sensing}

The lack of simple correlations between reflectance and individual water composition parameters in lakes Zug and Lucerne, due to their optical complexity, does not leave any chance for a purely "regressional" approach in the remote sensing of these lakes.

Drawing from the results obtained both in the PAR and the spectral regions, we nevertheless believe (see also Dekker, 1993, chap. 5) that a certain amount of pertinent information can be retrieved on some water quality parameters on the basis of existing and future remote captors, presented below in an increasing order of complexity.

\subsubsection{One-band sensors}

The well documented relationship (Kirk, 1981; Morel and Prieur, 1977) between reflectance in the PAR region $\left(R(0), R^{\prime \prime}(0), R^{\prime \prime \prime}(0)\right.$ or $R_{\text {ex }}$, see Table 2) and b/a has been be used to discriminate between lakes Zug and Lucerne. In type I marine waters, $b / a$ is strongly related to chlorophyll, which is not the case in lakes, where other optically active components do not necessarily covary in concentration with chlorophyll. The ratio gives direct access to neither $b$ nor $a$, so its usefulness will depend on the general knowledge of how it varies locally or regionally. This is, in fact, essentially a question of comparative limnology: in a new and unknown context, $R(0)$ will not be of much use; applied to lakes in Switzerland, it could be used to monitor some gross variations in water quality.

An analogue to $R(0)$ in the PAR domain could be found, for satellites, in the panchromatic channel of SPOT $(510-730 \mathrm{~nm})$, or perhaps even in AVHRR band 1 $(560-680 \mathrm{~nm})$. This latter avenue is being explored by one of us (Jaquet), with reference to the work of Prangsma et al., 1989, Spitzer et al., 1990, and Froidefond et al. (1993). It is clear that mono-band information will have its greatest potential in optically simple waters, such as turbid rivers or reservoirs. Jerome et al. (1989) state that reflectance measurements in the red $(650 \mathrm{~nm})$ seem to have some capability for estimating suspended mineral concentrations.

\subsubsection{Broad-band sensors}

The EXOTECH measurements carried out on Lake Zug and Lucerne have been shown to yield good estimates of water colour by means of "blue"/red ratio and chromaticity coordinates. In spite of the well-documented shortcomings of this last method (Bukata et al. 1983), it enabled us to clearly discriminate between our lakes, and even to distinguish some variability within Lake Zug (Fig. 10b).

For the sampling date concerned, the distinction in colour (green vs. blue-green, as shown by the chromaticity coordinate $y_{\mathrm{e}}$ in Fig. 11) corresponds to a contrast both in chlorophyll and TSS content. The possible additional roles of DOC and suspended minerals cannot yet be evaluated because we lack specific measurements of 


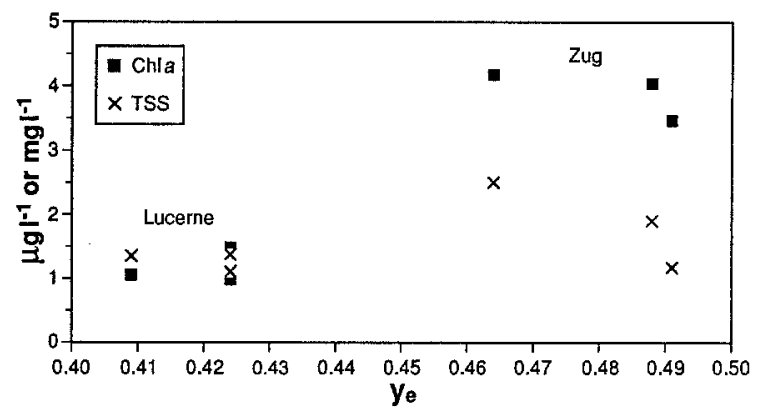

Figure 11. Relationship of chromaticity coordinate $y_{\mathrm{e}}$ (dimensionless) with total suspended solid $\left(\mathrm{mg} \mathrm{l}^{-1}\right)$ and chlorophyll $\left(\mu \mathrm{g} \mathrm{l}^{-1}\right)$ concentration

them. However, once they are available, it will be possible, for a given water body, to determine their variation and also their role in contributing to water colour.

Contextual information, i.e. the spatial colour patterns with respect to shore distance and river inputs, could also help to discriminate, say, between a greenness due either to chlorophyll or to allochtonous mineral particles.

Broad-band data is collected, in addition to hand-held or boom-mounted spectrometers (Bukata et al., 1988), by air- or satellite-borne captors (Dekker et al., 1991; Ferrari and Tassan, 1992; Dekker and Peters, 1993). A single Landsat TM scene, covering several tens of water bodies in the subalpine area (Jaquet and Zand 1989), could afford a good way of monitoring water quality within and between lakes using "ground-calibrated" chromaticity.

\subsubsection{Narrow-band sensors}

The unsatisfactory retrieval of Chl $a$, TSS and DOC from narrow-band LI-COR spectra in our lakes was because of the lack of appropriate optical cross-sections. When they are available, as in lakes Ontario and Ladoga (Bukata et al., 1991a), prediction levels have been shown to be quite acceptable.

If remote sensing is to be applied with its full potential to inland waters (van Stokkom et al., 1993), it is imperative that pertinent optical cross sections, along with their seasonal variabilities, be determined for each major water body (Bukata et al., 1991b). Work should also be done on the optochemical model (how to account for suspended mineral types, biogenic silica, or seston).

The minimal spectral resolution necessary for the computation of cross sections seem to be $20 \mathrm{~nm}$, which is equivalent to 15 channels between 410 and $690 \mathrm{~nm}$ (Bukata et al., 1983). Granted again the possibility of atmospheric correction, this measurement setup is available in airborne captors such as AVIRIS, and will be included in a new-generation instruments flying on future satellite platforms.

For natural waters with simpler optical characteristics (chlorophyll-dominated, or with DOC constant), the so-called due-isoplethic methodology of Bukata et al. (1981b), also based on the opto-chemical model, has the advantage of using only two $20 \mathrm{~nm}$ bands such as those of CZCS or upcoming SeaWiFS satellites (Octopus 1993). 


\section{Conclusions and recommendations}

With reference to the initial aims of this investigation, a certain number of conclusions will be presented, together with recommendations for further studies.

\section{Self-consistency and comparability}

The necessity of ground measurements to be time-concordant with the AVIRIS overpass required the involvement of several field teams, regretably equipped with dissimilar instrumentation. In addition, optical measurements could not always be performed on the same water masses as the in situ sampling. As a consequence, a fair amount of work had to be carried out to test the self-consistency of, and comparability between, all measurements, derived parameters and analytical results. Their "quality" has been ranked as good, satisfactory, acceptable or poor, as listed in table 1a (last line).

Secchi depth, parameters derived in a straightforward manner from PAR underwater measurements $\left(K_{\mathrm{d}}, z_{90}, \mu(0), a_{1}\right)$, as well as Chla and TSS concentration are considered to be "good", i. e. conforming to generally accepted quality standards. Owing to the need to transform scalar irradiance reflectance $R o(0)$ measured in Lake Lucerne into the more usual vector form $R(0)$, our reflectance estimates are considered as "satisfactory", in that they enable a clear discrimination between the lakes considered. In the absence of calibration of UV absorption in terms of DOC, $a_{3}$ is taken as "acceptable", as well as $b_{2}, b_{3}, c_{3}$ and $b / a$ : the ambient light near the surface has a yet undetermined influence on nephelometer readings, and the conversion of formazin turbidity units into scattering coefficient was taken from unconfirmed literature data. Our scattering estimates provide order-of-magnitude information on inherent optical properties, and permit, also, a discrimination between both lakes.

Finally, $c_{1}$ and $B$ are rated "poor"; the very low values found by transmissometry for the total attenuation coefficient $c_{1}$ in Lake Zug could indicate a perturbating effect of ambient light at the surface. As for the backscattering probability $B$, it was derived indirectly.

It is recommended that (a) sampling for water quality parameters and in situ optical measurements take place within a minimal time and space lag; (b) simultaneous measurements of vector and scalar irradiance be performed, to test the validity of relation Eq. (24); and (c) the influence of ambient light on surface nephelometer and transmissometer readings be evaluated, and a proper instrumentation developed to minimize it.

\section{Relationships between optical and water-quality parameters}

The relationship between Secchi depth measurements and the more elaborate $K_{\mathrm{k}}$ and $a$ coefficients agrees, in both lakes, with theory. Secchi depth is also correlated to the depth of sunshine penetration for remote sensing (Fig. 4b). It is influenced by TSS concentration but with a seemingly different sensitivity in both lakes (Fig. 6). 
If this kind of relationship could be generalized to other lakes and periods, Secchi depth could provide, in the absence of more sophisticated measurements, an approximation of the thickness of the layer affecting the satellite signal.

The additive properties of the attenuation coefficient for downwelling irradiance $K_{\mathrm{d}}$ were used to decipher the roles of chlorophyll, total suspended solids and dissolved organic carbon on the light regime. In spite of similar concentration in both lakes, TSS plays a much larger part in Lake Zug than in Lake Lucerne, where the impact of DOC is relatively more important.

The influence of total suspended solid and chlorophyll on colour hue and saturation could be established (Fig. 11) but not discriminated quantitatively. However, the position of lakes Zug and Lucerne on the $x$ vs. $y$ chromaticity diagram together with other water bodies of known trophic state (Fig. 10b) confirms the existence of a usable link between water colour and trophic level, which could be used for monitoring purposes.

\section{Baseline bio-optical characteristics}

Both lakes exhibit a marked vertical heterogeneity in total suspended solids, chlorophyll and, at least, turbidity profiles. There is also, in Lake Zug, a decrease in turbidity and in increase in transparency from north to south, related to changes in anthropic loadings from the watershed.

Considering lakewide mean characteristics, Lake Zug is optically quite different from Lake Lucerne: although suspended solid concentrations are of the same order of magnitude, transparency is lower in Lake Zug, whereas $b / a$ or reflectance is substantially higher in Lake Lucerne, which has lower concentrations of pigments and dissolved organics depressing the levels of absorption. In the scattering/absorption continuum of Fig. 7, Lake Lucerne stands at the lower extreme, whereas Zug is closer to Lake Ontario and to the oligotrophic members of Loosdrecht lakes. In terms of colour, the contrast is also clear between blue-green Lake Lucerne (hue at $510 \mathrm{~nm}$ ) and green Lake Zug (hue between 540 and $560 \mathrm{~nm}$ ), in conformity to their respective trophic level.

\section{Retrieval of inherent optical properties from $R(0)$}

At the given date, the scattering to absorption ratio in the PAR region was found to be proportional to $R(0)$ through a mean coefficient applicable to both lakes. Due to the vertical heterogeneity of bio-optical properties, it was felt that the method advocated by Kirk (1981) to retrieve $b$ and $a$ from reflectance at mid-euphotic depth could not be applied here. Hence, in the absence of in situ optical measurements (giving $a$ or $b$ ), and without an a priori knowledge of the lakes, the ratio in the PAR region would only be of a limited interest, merely indicating whether the lakes are absorption- or scattering-dominated. However, in the case of waterbodies with known optical behaviour, a non-spectral $b / a$ ratio gained, for instance, from monoband or panchromatic satellite reflectance could be used to map contrasting waterquality "provinces" within large lakes. 


\section{Applicability of an optochemical model}

A statistical correlation approach between optics and water quality was used in this work only within the framework of theory (however imperfect, see for instance, Figs. 5, 6 or 7) and not with a view to deriving empirical relationships, which would have been applicable only to the date and sites considered in the AVIRIS campaign. In order to gain generality, it is imperative to follow the approach of optochemical modelling, which establishes the link between simplified water composition and reflectance spectra.

Owing to the lack of site-specific optical cross-sections for the lakes studied, we had to use, in our modelling trials, those available for other lakes, with the aggravating factor that reliable data was missing for the dissolved organics, and none was at our disposal for suspended minerals. In these conditions, it is not surprising that spectra modelled on the basis of known Chla, TSS and DOC concentrations did not fully coincide with measured spectra.

Therefore, we recommend optochemical modelling as the only sensible way to link the realm of optics and water quality, and as a prerequisite to any operationally valid remote sensing application. This calls for a somewhat novel approach to in situ water quality studies: in a given waterbody, it will be necessary to include reliable estimates of chlorophyll, dissolved organics and suspended minerals, together with their typology and data on their spatio-temporal variability. High-resolution reflectance spectra collected simultaneously will then make it possible to compute valid optical cross-sections.

\section{Relevance to remote sensing}

A critical examination of the data collected during the AVIRISWISS campaign and of the pertinent theoretical models opens up some perspectives for the monitoring of subalpine lakes by satellite, as recommended recently by Tilzer and Bossard (1992) and van Stokkom et al. (1993).

Starting from an optochemical model or at least a sound knowledge of the general, or dominant bio-optical behaviour of the waterbody, it is possible to monitor some variations of water quality. The extent of this monitoring will depend, understandably, on the radiometric possibilities of the air- or satellite-borne captor as well as on the availability of an atmospheric correction scheme (this last prerequisite has not be dealt with in this study).

Satellites currently in operation collect the visible reflected radiance in one (AVHRR, SPOT panchromatic) or several broad bands (Landsat TM, SPOT XS). Mono-band information could, by analogy with our PAR results, help follow the variations in scattering to absorption ratio or turbidity in extreme cases. The possibility of expressing a fair estimate of chromaticity from broad-band, hand-held spectrometers could be extended to Landsat TM data and used to monitor withinand between-lakes variations in colour related to trophic state changes. Finally, coastal marine applications have demonstrated the potential of Landsat TM in chlorophyll retrieval thanks to the application of local optical models, even in the presence of high concentrations of dissolved organics (Ferrari and Tassan., 1992; Tassan and Ribera d'Alcala, 1993). 
An important and unique asset of remotely-derived data should be stressed here: it is the possibility of portraying spatial heterogeneities in water colour or temperature (Strub et al., 1984), at a horizontal scale as fine as tens of metres. This socalled contextual information represents a powerful tool to interpret otherwise ambiguous color patterns, by considering their position with respect to possible inputs of matter or energy from the watershed.

The planned development of new sensors, some of which are dedicated to water measurements with provision for atmospheric correction (SeaWiFS, to be launched in 1994; MERIS, to be flown on european ENVISAT in a decade), will certainly make surface water monitoring of oceans and large lakes a reality.

\section{ACKNOWLEDGEMENTS}

The authors are indebted to K. Itten, Institute of Geography, University of Zurich, for including the limnological leg into the AVIRISWISS project, and to the teams from Canton of Zug (R. Beck, H. Flückiger, A. Frei, E. Seiler, G. Weilenmann and F. Zeder), EAWAG, Swiss Federal Institute of Technology (VAM), Universities of Zurich, Geneva and Neuchâtel for their assistance in the field and the laboratory. We thank $\mathbf{J}$. Metzger for his apt and careful redrafting of the figures. Critical reading by two reviewers is gratefully acknowledged.

\section{REFERENCES}

Alföldi, T.T. and Munday, J.C., 1978. Water quality analysis by digital chromaticity mapping of Landsat data. Can. J. Earth Sci., 4(2): 108-126.

Bannister, T. T., 1990. Empirical equations relating scalar irradiance to a, b/a, and solar zenith angle. Limnol. Oceanogr., 35(1):173-177.

Bapst, A., 1987. Le Lac de Neuchâtel: Physico-chimie et turbidimétrie des eaux. Concentration, minéralogie et granulométrie des particules en suspension. $\mathrm{PhD}$ thesis, Univ. Neuchâtel, $101 \mathrm{p}$.

Beeton, A.M., 1957. Relationship between Secchi disc readings and light penetration in Lake Huron. Trans. Am. Fish. Soc., 87:73-79.

Berthon, J.-F. and A. Morel, 1992. Validation of a spectral light-photosynthesis model and use of the model in conjunction with remotely sensed pigment observations. Limnol. Oceanogr., $37(4): 781-796$.

Bossard, P., Steiner, D. and Uhde, M., 1991. Die horizontale Verteilung von Schwebstoffen im Epilimnion des Vierwaldstättersees. Untersuchungen im Rahmen des Projektes AVIRISwiss 91. EAWAG Jahresbericht: $40-41$.

Bowling, L. C., Steane, M. S. and Tyler, P.A., 1986. The spectral distribution and attenuation of underwater irradiance in Tasmanian inland waters. Freshwater Biol., 16:313-335.

Bricaud, A., Morel, A. and Prieur, L., 1981. Absorption by dissolved organic matter of the sea (yellow substance) in the UV and visible domain. Limnol. Oceanogr., 16(1):43-53.

Bukata, R. P., Jerome, J. H., Bruton, J. E. and Jain, S. C., 1979: Determination of inherent optical properties of Lake Ontario coastal waters. Appl. Opt., 18(23):3926-3932.

Bukata, R. P., H. H. Jerome, J.E. Bruton, S. C. Jain and H. H. Zwick, 1981a. Optical water quality model of Lake Ontario. 1: Determination of the optical cross-sections of organic and inorganic particulates in Lake Ontario. Appl. Opt., 20(9):1696-1703.

Bukata, R. P., J.H. Jerome, J. E. Bruton, S. C. Jain and H. H. Zwick, 1981b. Optical water quality model of Lake Ontario. 2: Determination of chlorophyll $a$ and suspended mineral concentrations of natural waters from submersible and low altitude optical sensors. Appl. Opt., 20(9): $1704-1714$.

Bukata, R.P., J.E. Bruton and J.H. Jerome, 1983. Use of chromaticity in remote measurements of water quality. Rem. Sens. Env., 13:161-177. 
Bukata, R.P., J.E. Bruton and J. H. Jerome, 1985. Application of direct measurements of optical parameters to the estimation of lake water quality indicators. Envir. Canada, Scient. Series no. $140,35 \mathrm{p}$.

Bukata, R.P., Jerome, J.H. and Bruton, J.E., 1988. Particulate concentrations in Lake St. Clair as recorded by a shipborne multispectral optical monitoring system. Rem. Sens. Env., 25: $201-229$.

Bukata, R.P., J. H. Jerome, K. Y. Kondratyev and D. V. Pozdnyakov, 1991a. Estimation of organic and inorganic matter in inland waters: optical cross-sections of lakes Ontario and Ladoga. $\mathbf{J}$. Great Lakes Res., 17(4):461-469.

Bukata, R. P., J.H. Jerome, K. Y. Kondratyev and D. V. Pozdnyakov, 1991b. Satellite monitoring of optically-active components of inland waters: an essential input to regional climate change impact studies, J. Great Lakes Res., 17(4):470-478.

Davies-Colley, R.J., 1988. Measuring water clarity with a black disk. Limnol. Oceanogr., 33(4): $616-623$.

Davies-Colley, R.J., W.N. Vant and R.J. Wilcock, 1988. Lake water color: comparison of direct observations with underwater spectral irradiance. Water, Res. Bull. AWRA, 24(1): $11-18$.

Dekker, A.G., 1993. Detection of optical water quality parameters for eutrophic waters by high resolution remote sensing. Thesis, Free University of Amsterdam, $222 \mathrm{p}$.

Dekker, A. G., T.J. Malthus and E. Seyhan, 1991. Quantitative modeling of inland water quality for high-resolution MSS systems. IEEE Trans. Geosci. Rem. Sens., 29(1):89-95.

Dekker, A. G., T. J. Malthus, M. M. Wijnen and E. Sehyan, 1992. The effect of spectral bandwidth on the spectral signature analysis of inland waters. Rem. Sens. Env., 41:211-225.

Dekker, A. G. and Peters, S. W. M., 1993. The use of Thematic Mapper for the analysis of eutrophic lakes: a case study in the Netherlands. Int. J. Rem. Sens., 14(5):799-821.

Di Toro, D.M., 1978. Optics of turbid estuarine waters: approximations and applications. Water Research, 12:1059-1068.

Fahrni, H. P. and Liechti, P., 1984. Der aktuelle Zustand des Zugersees. BUS Bull., 5:3-8.

Ferrari, G.M. and Tassan, S., 1992. Evaluation of the influence of yellow substance absorption on the remote sensing of water quality in the Gulf of Naples: a case study. Int. J. Rem. Sens., 13(12): $2177-2189$.

Froidefond, J. M., Castaing, P., Jouanneau, J. M. and Prud'homme, R., 1993. Method for the quantification of suspended sediments from AVHRR NOAA-11 satellite data. Int. J. Rem. Sens., $14(5): 885-894$.

Gale, R. M., 1978. Water quality surveys. IHD-WHO Studies and reports in hydrology, UNESCO, Paris, $350 \mathrm{p}$.

Gitelson, A., 1992. The peak near $700 \mathrm{~nm}$ on radiance spectra of algae and water: relationships of its magnitude and position with chlorophyll concentration. Int. J. Rem. Sens., 13(17): $3367-$ 3373.

Gordon, H. R., 1978. Remote sensing of optical properties in continuously statified waters. Appl. Opt., 17(12): 1893-1897.

Gordon, H. R., 1980. Remote sensing of optical properties of a stratified ocean: an improved interpretation. Appl. Opt., 19(20):3428-3430.

Gordon, H.R. and McCluney, W. R., 1975. Estimation of the depth of sunlight penetration in the sea for remote sensing. Appl. Opt., 14(2): 413-416.

Gordon, H. R., O.B. Brown and M.M. Jacobs, 1975. Computed relationships between the inherent and apparent optical properties of a flat homogeneous ocean. Appl. Opt., 14(2): $417-427$.

Højerslev, N., 1975. A spectral light absorption meter for measurements in the sea. Limnol. Oceanogr., 20:1024-1034.

Imboden, D. M., Stotz, B. and Wüest, A., 1988. Hypolimnic mixing in a deep alpine lake and the role of a storm event. Verh. Int. Verein. Limnol, 23:67-73.

Itten, K. I., Meyer, P., Staenz, K., Kellenberger, T. and Schaepman, M., 1993. Evaluation of AVIRISwiss-91 Campaign Data. Third Annual JPL Airborne Geoscience Workshop, Pasadena. JPL Publ. 92-14, 1:108-110.

Jaquet, J. M., 1989. Limnologie et télédétection: situation actuelle et développements futurs. Rev. Sci. Eau, 2:457-481. 
Jaquet, J.-M. and Zand, B., 1989. Colour Analysis of Inland Waters Using Landsat TM Data. ESA SP-1102:57-67.

Jerlov, N. G., 1968. Optical oceanography. Elsevier publ., London, 194 p.

Jerlov, N.G., 1974. Significant relationships between optical properties of the sea. In Optical aspects of oceanography: 77-94, Ed. by Jerlov and Steemann-Nielsen, Academic Press.

Jerome, J.H., Bruton, J. E. and Bukata, R.P., 1989. Optical monitoring of water quality in inland lakes. Proceedings of the 12th Canadian Symp. on Remote Sensing: 2799-2803.

Jewson, D.H., Talling, J.F., Dring, M. J., Tilzer, M. M., Heaney, S. I. and Cunningham, C., 1984. Measurements of photosynthetically available radiation in freshwater: comparative tests of some current instruments used in studies of primary production. J. Plankton Res., $6(2): 259-273$.

Kirk, J. T. O., 1981. Estimation of the scattering coefficient of natural waters using underwater irradiance measurements. Aust. J. Mar. Freswater Res., 32:533-539.

Kirk, J. T. O., 1983. Light and photosynthesis in aquatic ecosystems. Cambridge Univ. Press, 401 p.

Kirk, J.T. O., 1984. Dependence of relationship between inherent and apparent optical properties of water on solar altitude. Limnol. Oceanogr., 29(2):350-356.

Kirk, J. T. O., 1991. Volume scattering function, average cosines, and the underwater light field. Limnol. Oceanogr., 36(3): 455-467.

Koenings, J.P. and Edmundson, J.A., 1991. Secchi disk and photometer estimates of light regimes in Alaskan lakes: effects of yellow color and turbidity. Limnol. Oceanogr., 3681): $91-105$.

Krumbein, W.C. and Graybill, F.A., 1965. An introduction to statistical models in Geology. McGraw-Hill, 475 p.

Lorenzen, M.W., 1980. Use of chlorophyll-Secchi disk relationships. Limnol. Oceanogr., 25(2):371-372.

Mittenzwey, K. H., Gitel'son, A. A., Lopatchenko, A. A., Sukhorukov, B. L. and Voigt, T., 1988. Insitu monitoring of water quality on the basis of spectral reflectance. Int. Rev. ges. Hydrobiol., $73: 61-72$.

Morel, A. and L. Prieur, 1977. Analysis of variations in ocean color. Limnol. Oceanogr, 22(4): $709-722$.

Morel, A. and Berthon, J.F., 1989. Surface pigments, algal biomass profiles, and potential production of the eueuphotic layer: Relationships reinvestigated in view of remote sensing applications. Limnol. Oceanogr., 34(8): 1545-1562.

Octopus Project, 1993. Proposal for a Joint European Programme on Ocean Colour Techniques for Observation, Processing and Utilization Systems. OCTOPUS Tech. Series, vol 1, IRSA, JRC CEC, Ispra.

Prangsma, G. J. and Roozekrans, J. N., 1989. Using NOAA AVHRR imagery in assessing water quality parameters. Int. J. Rem. Sens., 10(4-5):811-818.

Preisendorfer, R. W., 1986. Secchi disk science: Visual optics of natural waters. Limnol. Oceanogr., $31(5): 909-926$.

Prieur, L., 1976. Transfert radiatif dans les eaux de mer. Application à la détermination de paramètres optiques caractérisant leur teneur en substances dissoutes et leur contenu en particules. Thèse, Uni. P. et M. Curie, 243 pp.

Prieur, L. and S. Sathyendranath, 1981. An optical classification of coastal and oceanic waters based on the spectral absorption curves of phytoplankton pigments, dissolved organic matter, and other particulate materials. Limnol. Oceanogr., 26(4):671-689.

Sathyendranath, S. and Platt, T., 1989. Remote sensing of ocean chlorophyll: consequence of a nonuniform pigment profile. Appl. Opt., 28(3): 490-495.

Sathyendranath, S., L. Prieur and A. Morel, 1989. A three-component model of ocean colour and its application to remote sensing of phytoplankton in coastal waters. Int. J. Rem. Sens., 10(8): $1373-1394$.

Schanz F., 1982. Light conditions in Lake Zürich 1979-1981. Part I: Secchi disk transparency. Vierteljahrsschr. Naturforsch. Ges. Zürich 127:357-367.

Schanz, F., 1985. Vertical light attenuation and phytoplankton development in Lake Zürich. Limnol. Oceanogr., 30(2):299-310.

Schanz, F., 1986. Depth distribution and associated spectral changes in downward irradiance in Lake Zürich (1980/81). Hydrobiologia, 134:183-192. 
Smith, R.C. and Baker, K. S., 1978. The bio-optical state of ocean waters and remote sensing. Limnol. Oceanogr., 23(2): 247-259.

Smith, R. C. and Baker, K. S., 1981. Optical properties of the clearest natural waters. Appl. Opt., $20(2): 177-184$.

Smith, R. C., J. E. Tyler and C. R. Goldman, 1973. Optical properties and color of Lake Tahoe and Crater Lake. Limnol. Oceanogr., 18(2):189-199.

Spitzer, D., Laane, R. and Roozekrans, J. N., 1990. Pollution monitoring of the North Sea using NOAA/AVHRR imagery. Int. J. Rem. Sens., 11(6): 967-977.

Strub, T., Powel, T.M. and Abbott, M.R., 1984. Temperature and transport patterns in Lake Tahoe: satellite imagery, field data and a dynamical model. Verh. Int. Verein. Limno, 22: $112-118$.

Tassan, S. and Ribera d'Alcala, M., 1993. Water quality monitoring by Thematic Mapper in coastal environments. A performance analysis of local biooptical algorithms and atmospheric correction procedures. Rem. Sens. Environ., 45:177-191.

Tilzer, M.M. and Bossard, P., 1992. Large lakes and their sustainable development. Aquatic Sci., 54(2):91-103.

Tyler, J.E., 1968. The Secchi disc. Limnol. Oceanogr., 13(1):1-6.

Uehlinger, U., 1985. An in situ pulse light fluorometer for chlorophyll determination as a monitor for vertical and horizontal phytoplankton distribution in lakes. J. Plankt. Res., 7(5): 605-615.

Vangriesheim, A., Gouillou, J.P. and Prieur, L., 1992. A deep-ocean nephelometer to detect bottom and intermediate nepheloid layers. Deep Sea Res., 39:1403-1416.

van Stokkom, H.T. C., Stokman, G. N. M. and Hovenier, J. W., 1993. Quantitative use of passive remote sensing over coastal and inland water bodies. Int. J. Rem. Sens., 14(3):541-564.

Vertucci, F.A. and Likens, G.E., 1989. Spectral reflectance and water quality of Adirondack mountain region lakes. Limnol. Oceanogr., 34(8):1656-1672.

Volienweider, R.A., 1960: Beiträge zur Kenntnis optischer Eigenschaften der Gewässer und Primärproduktion. Mem. Ist. Ital. Idrobiol., 12:201-244.

Weidemann, A. D., Bannister, T. T., Effler, S. W. and Johnson, D. L., 1985. Particulate and optical properties during $\mathrm{CaCO}_{3}$ precipitation in Otisco Lake. Limnol. Oceanogr., 30(5):1078-1083.

Weidemann, A. D. and Bannister, T. T., 1986. Absorption and scattering coefficients in Irondequoit Bay. Limnol. Oceanogr., 31(3):567-583.

Wyszecki, G. and Stiles, W.S., 1982. Color science: concepts and methods, quantitative data and formulae. J. Wiley, $950 \mathrm{p}$.

Zaneveld, J. R. V., 1989. An asymptotic closure theory for irradiance in the sea and its inversion to obtain the inherent optical properties. Limnol. Oceanogr., 34(8):1442-1452.

Received 18 October 1993;

manuscript accepted 7 February 1994.

\section{List of symbols}

Symbol designation

$a_{\mathrm{i}} \quad$ Total absorption coefficient (i: index for various estimates)

$a_{\text {DOC }}$ Absorption coefficient due to DOC

$b_{\mathrm{i}} \quad$ Total scattering coefficient (i: index for various estimates)

$b_{\mathrm{b}} \quad$ Backscattering coefficient

$B \quad$ Backscattering probability

$c_{\mathrm{i}} \quad$ Total or beam attenuation coefficient $(a+b)$ (i: as above)

$D(\mu(0))$ Proportionality factor linking $R(0)$ to $b_{b} / a$

$D^{\prime} \quad$ Proportionaliy factor linking $R(0)$ to $b / a$

$D^{\prime} \quad$ Computed value of $D^{\prime}$

$E_{\mathrm{d}} \quad$ Downwelling vector irradiance

$E_{\mathrm{d}}(\mathrm{i}) \quad$ Downwelling irradiance in EXOTECH ith channel
Equation Units

\begin{tabular}{|c|c|}
\hline $5,21,28$ & $\mathrm{~m}^{-1}$ \\
\hline $32 a$ & $\mathrm{~m}^{-1}$ \\
\hline $6,22,24$ & $\mathrm{~m}^{-1}$ \\
\hline 7 & $\mathrm{~m}^{-1}$ \\
\hline 7 & - \\
\hline 20,25 & $\mathrm{~m}^{-1}$ \\
\hline $8 \mathrm{~b}$ & - \\
\hline $10 \mathrm{~b}$ & - \\
\hline $10 \mathrm{a}$ & - \\
\hline . & $\mu \mathrm{E} \mathrm{m}^{-2} \mathrm{~s}^{-1}$ \\
\hline
\end{tabular}


$E_{\mathrm{n}} \quad$ Net irradiance $\left(E_{\mathrm{d}}-E_{\mathrm{u}}\right.$ or $\left.E o_{\mathrm{d}}-E o_{u}\right)$

Eo Scalar irradiance $\left(E o_{\mathrm{d}}+E o_{\mathrm{u}}\right)$

$E o_{d} \quad$ Downwelling scalar irradiance

$E \mathrm{O}_{\mathrm{u}} \quad$ Upwelling scalar irradiance

$E_{\mathrm{u}} \quad$ Upwelling vector irradiance

$F \quad$ Function of $\mu(0)$ linking $R o(0)$ and $R(0)$

$K_{\mathrm{c}} \quad$ Partial attenuation coefficient for chlorophyll

$k_{\mathrm{c}} \quad$ Specific attenuation coefficient for chlorophyll

$K_{\mathrm{cc}} \quad$ Partial attenuation coefficient for chloropyll + covarying substances

$k_{\mathrm{cc}} \quad$ Specific attenuation coefficient for chlorophyll + covarying substances

$K_{\mathrm{d}} \quad$ Attenuation coefficient of downwelling vector irradiance

$K_{\mathrm{e}} \quad$ Attenuation coefficient of net vector irradiance

$K_{\mathrm{k}} \quad$ Photopic attenuation coefficient

$K_{\mathrm{m}} \quad$ Partial attenuation coefficient $\left(=K_{\mathrm{w}}+K_{\mathrm{n}}\right)$

$K_{\text {np }} \quad$ Partial attenuation coefficient for non particulates

$K_{\mathrm{n}} \quad$ Partial attenuation coefficient for substances independent from Chla

$K_{\mathrm{p}} \quad$ Partial attenuation coefficient for particulates

$k_{\mathrm{p}} \quad$ Specific attenuation coefficient (cross-ection) for TSS

$K_{\mathrm{w}} \quad$ Partial attenuation coefficient for pure water .

$K_{\mathrm{y}} \quad$ Partial attenuation coefficient for DOC

$k_{\mathrm{y}} \quad$ Specific attenuation coefficient for DOC

$K_{z} \quad$ Partial attenuation coefficient for chlorophyll + covarying substances

$k_{\mathrm{z}} \quad$ Specific attenuation coefficient for chlorophyll + covarying substances

$L_{\mathrm{u}}$ (i) Upwelling radiance in EXOTECH ith channel

$p \quad$ Percentage of $E_{\mathrm{d}}$ at depth $z_{\text {sd }}$

$Q \quad$ Factor for conversion of radiance into irradiance

$q_{\mathrm{t}} \quad$ Proportionality factor linking $z_{90}^{\prime \prime}$ to $z_{\mathrm{sd}}(-(1 / \ln (\mathrm{p}))$

$q_{\mathrm{t}}^{\prime} \quad$ Estimate of $q_{\mathrm{t}}$ derived from $R(0)$

$q_{\mathrm{r}} \quad$ Proportionality factor linking $z^{\prime \prime}{ }_{g 0}$ to $z_{\mathrm{s} d}$ (empirical)

$R(0) \quad$ Vector irradiance reflectance at $0 \mathrm{~m}$ for PAR region

$R_{\mathrm{u}}(0) \quad$ Unweighted estimate of $R(0)$ over $z_{90}$

$R_{\mathrm{w}}(0) \quad$ Weighted estimate of $R(0)$ over $z_{90}$

$R(0, \lambda) \quad$ Spectral vector irradiance reflectance

$R^{\prime}(0, \mathrm{i}) \quad$ TM ith band-equivalent irradiance reflectance ( $\left.\mathrm{LI}-\mathrm{COR}\right)$

$R^{\prime \prime}(0) \quad$ PAR-equivalent irradiance reflectance (LI-COR)

$R^{\prime \prime \prime}(0) \quad(450-690 \mathrm{~nm})$-equivalent irradiance reflectance (LI-COR)

$R_{\mathrm{e}}$ (i) $\quad$ Above-water irradiance reflectance (EXOTECH ith band)

$R_{\mathrm{ex}} \quad(450-690 \mathrm{~nm})$-equivalent irradiance reflectance (EXOTECH)

$R o(0) \quad$ Scalar irradiance reflectance at $0 \mathrm{~m}$ for PAR region

$S \quad$ Factor for conversion of FTU turbidity into scattering

$\operatorname{Tr}_{\lambda} \quad$ Transmissivity at wavelength $\lambda$

$\{x, y, z\}$ Chromaticity coordinates, CIE 1931 norms

$z_{\mathrm{eu}} \quad$ Euphotic depth

$z_{\mathrm{m}} \quad$ Mid-euphotic depth

$z_{90} \quad$ Depth of sunshine penetration for remote sensing (DSPRS) $z_{90}$ equals $z$ where $E_{\mathrm{d}}(z)=E_{\mathrm{d}}(0) \cdot 0.37$

$z_{00}^{\prime} \quad$ Estimate of DSPRS $\left(\approx \lambda K_{\mathrm{d}}\right)$

$z_{90}^{\prime \prime} \quad$ Estimate of DSPRS $\left(=q_{\mathrm{t}} \cdot z_{\mathrm{sd}}\right)$

\begin{tabular}{|c|c|}
\hline- & 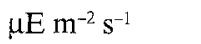 \\
\hline- & $\mu \mathrm{E} \mathrm{m}^{-2} \mathrm{~s}^{-1}$ \\
\hline- & $\mu \mathrm{E} \mathrm{m} \mathrm{m}^{-2} \mathrm{~s}^{-1}$ \\
\hline- & $\mu \mathrm{E} \mathrm{m}^{-2} \mathrm{~s}^{-1}$ \\
\hline - & $\mu \mathrm{E} \mathrm{m}^{-2} \mathrm{~s}^{-1}$ \\
\hline 24 & - \\
\hline $33 a$ & $m^{-1}$ \\
\hline $33 \mathrm{a}$ & $\mathrm{m}^{2} \mathrm{mg}^{-1}$ \\
\hline $33 d$ & $m^{-1}$ \\
\hline $33 \mathrm{~d}$ & $\mathrm{~m}^{2} \mathrm{mg}^{-1}$ \\
\hline 2 & $\mathrm{~m}^{-1}$ \\
\hline- & $\mathrm{m}^{-1}$ \\
\hline $27 a$ & $\mathrm{~m}^{-1}$ \\
\hline $33 a$ & $\mathrm{~m}^{-1}$ \\
\hline $31 \mathrm{a}$ & $m^{-1}$ \\
\hline $33 \mathrm{a}$ & $\mathrm{m}^{-1}$ \\
\hline $31 a$ & $m^{-1}$ \\
\hline $31 \mathrm{a}$ & $\mathrm{m}^{2} \mathrm{~g}^{-1}$ \\
\hline $31 \mathrm{a}$ & $\mathrm{m}^{-1}$ \\
\hline 31,32 & $\mathrm{~m}^{-1}$ \\
\hline $32 b$ & $\mathrm{~m}^{2} \mathrm{~g}^{-1}$ \\
\hline $33 b$ & $\mathrm{~m}^{-1}$ \\
\hline $33 a$ & $\mathrm{~m}^{2} \mathrm{mg}^{-1}$ \\
\hline 18 & $\mathrm{~W} \mathrm{~m} \mathrm{~m}^{-2} \mathrm{sr}^{-1} \mathrm{~nm}^{-1}$ \\
\hline $29 b$ & \\
\hline 18 & $\mathrm{sr}$ \\
\hline $29 b$ & - \\
\hline 30 & - \\
\hline $29 \mathrm{c}$ & \\
\hline 4 & - \\
\hline $12 \mathrm{a}$ & - \\
\hline $12 \mathrm{~b}$ & - \\
\hline 4 & - \\
\hline 15 & - \\
\hline 16 & - \\
\hline 17 & - \\
\hline 18 & - \\
\hline 19 & - \\
\hline 23 & - \\
\hline 22 & FTU $\mathrm{m}^{-1}$ \\
\hline $20,21,25$ & - \\
\hline- & \\
\hline- & $\mathrm{m}$ \\
\hline- & $\mathrm{m}$ \\
\hline- & $\mathrm{m}$ \\
\hline 11 & $\mathrm{~m}$ \\
\hline $29 a$ & $\mathrm{~m}$ \\
\hline
\end{tabular}


$\alpha \quad$ Proportionality factor linking chlorophyll to covarying

\section{$\Gamma \quad$ Contrast transmittance factor}

$\mu(0) \quad$ cosine of zenith angle in water $\left(\theta^{\prime}\right)$

$\mu_{\mathrm{b}} \quad$ Aberage cosine

$\theta \quad$ Sun zenith angle

$\theta^{\prime} \quad$ Zenith angle in water

$\begin{array}{ll}33 a & - \\ 27 b & - \\ 1 b & - \\ 3 & - \\ 1 a & \text { degree } \\ 1 \mathrm{a} & \text { degree }\end{array}$

